\title{
Weathering Tight Economic Times: The Sales Evolution of Consumer Durables Over the Business Cycle
}

\author{
BARBARA DELEERSNYDER \\ Postdoc Researcher Fellow in Marketing, Erasmus University Rotterdam, P.O. Box 1738, \\ 3000 DR Rotterdam, The Netherlands \\ E-mail: Bdeleersnyder@fbk.eur.nl \\ MARNIK G. DEKIMPE \\ Professor of Marketing, Catholic University of Leuven, Naamsestraat 69, 3000 Leuven, Belgium; \\ Professor of Marketing Management, Erasmus University Rotterdam, The Netherlands \\ E-mail: Marnik.Dekimpe@econ.kuleuven.ac.be \\ MIKLOS SARVARY \\ Associate Professor of Marketing, INSEAD, Boulevard de Constance, 77305, Fontainebleau, France \\ E-mail: Miklos.Sarvary@insead.edu \\ PHILIP M. PARKER \\ The Eli Lilly Chaired Professor of Innovation, Business and Society, INSEAD, Boulevard de Constance, \\ 77305, Fontainebleau, France \\ E-mail:Phil.Parker@insead.edu
}

\begin{abstract}
Despite their obvious importance, not much marketing research focuses on how business-cycle fluctuations affect individual companies and/or industries. Often, one only has aggregate information on the state of the national economy, even though cyclical contractions and expansions need not have an equal impact on every industry, nor on all firms in that industry. Using recent time-series developments, we introduce various measures to quantify the extent and nature of business-cycle fluctuations in sales. Specifically, we discuss the concept of cyclical volatility, and derive a dynamic comovement elasticity between the economy as a whole and the cyclical fluctuations in various performance series. To further enhance our understanding of how consumers adjust their purchasing behavior across different phases of the business cycle, two other notable features related, respectively, to the relative size of the peaks and troughs and the rate of change in upward and downward parts of the cycle, are explicitly considered. Of specific interest in this respect are the notion of deepness and steepness asymmetry. We apply these concepts to a broad set (24) of consumer durables, for which we analyze the cyclical sensitivity in their sales evolution. In that way, we (i) derive a novel set of empirical generalizations, and (ii) test different marketing theory-based hypotheses on the underlying drivers of cyclical sensitivity.

Consumer durables are found to be more sensitive to business-cycle fluctuations than the general economic activity, as expressed in an average cyclical volatility of more than four times the one in GNP, and an average dynamic comovement elasticity in excess of 2 . This observation calls for an explicit consideration of cyclical variation in durable sales. Interestingly, the combined evidence across all durables suggests that asymmetry is present in the speed of up- and downward movements, as durable sales fall much quicker during contractions than they recover during economic expansions. Finally, key variables related to the industry's pricing activities, the nature of the durable (convenience vs. leisure), and the stage in a product's life cycle tend to moderate the extent of cyclical sensitivity in durable sales patterns.
\end{abstract}


Key words. business cycles, sales evolution, consumer durables, time-series econometrics

JEL Classification: C12, C22, C3, M21, M31

\section{Introduction}

The renewed fear for a widespread economic downturn reminds companies that macroeconomic developments can be among the most influential determinants of a firm's activities and performance. In a recent Business Week survey, US companies report profits that are up to $30 \%$ down from previous year, with an especially dramatic drop in sectors such as telecommunication, computer technology and pharmaceuticals (August 5, 2002, p. 60). Similarly, The Economist reports that US retail sales dropped 3.7\% in November 2001, the sharpest month-to-month decline since 1992 (March 9, 2002,p. 4). Given the size of these reductions, it should come as no surprise that management feels the heat to actively respond to such economic downturns. Shama (1993), for example, found that almost all managers he surveyed modify their marketing strategy in response to economic contractions. Still, most companies also indicated they did not use any systematic procedure to determine the impact of such economic contraction on their specific business. Put differently, while companies feel a strong need to make some changes to their marketing tactics and strategies in economic downturns, they are often at a loss on how to adequately assess the impact of these contractions. Yet, how they perceive the environmental threat posed by a downturn will drive to a considerable extent whether and how they will adjust their behavior (Dutton and Duncan, 1987).

In the academic marketing literature, one occasionally accounts for long-run evolutions in macro-economic variables generally associated with demand (e.g. Dekimpe and Hanssens, 1995a; Franses, 1994). Much less attention has been devoted to the sensitivity of performance and marketing support to cyclical variations in the economy. ${ }^{1}$ In a recent review of three leading marketing journals (Journal of Marketing, Journal of Marketing Research, Marketing Science), Srinivasan, Lilien, and Rangaswamy (2004) found only three publications on a topic related to economic contractions, with the most recent one published in 1979. This general neglect of business-cycle fluctuations in the marketing literature is surprising, as they may affect both consumers' and companies' activities.

Alternatively, in the economics literature, quite some researchers have examined the relation between aggregate business cycles and various macro-economic indicators (see e.g. Mankiw, 1985; Stock and Watson, 1999). However, very few efforts have been made to explicitly consider the relationship at a more disaggregate micro-level that represents the immediate working domain for individual companies. Such a more disaggregate analysis is called for, as disaggregate relations may well differ from the aggregate ones (Berman and Pfleeger, 1997; Jacobs, 1998; Mascarenhas and Aaker, 1989; Shama, 1993). After all, it has been argued that in a national downturn, only $60 \%$ of all industrial sectors are actually in a

1 Cyclical variations in the economy have been studied extensively by macro-economists, but these studies concentrate on aggregate economic variables such as GDP (as we will review more extensively in Section 2), while we concentrate on individual durable categories. Marketing papers considering the effect of cyclical variations in the economy include Clark, Freeman, and Hanssens (1984), Coulson (1979), Cundiff (1975), Devinney (1990), and Yang (1964). 


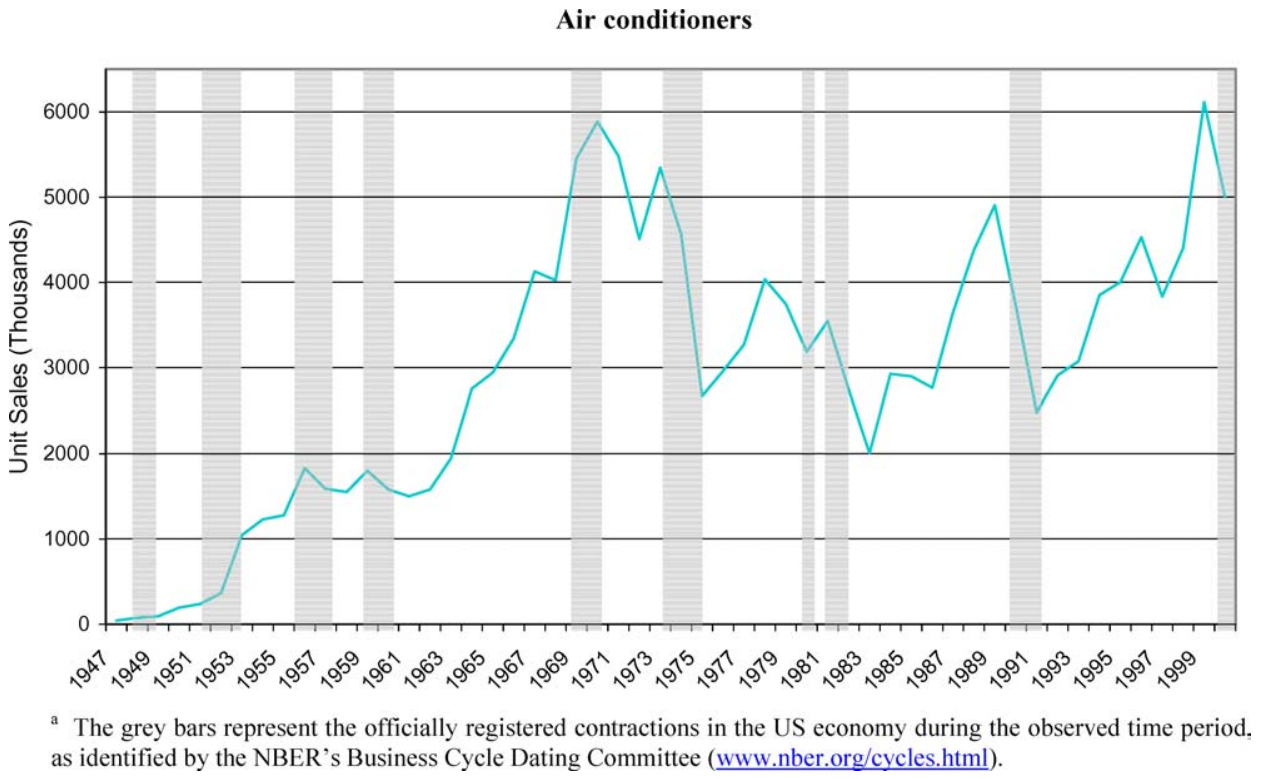

Figure 1. Postwar sales evolution of US air conditioners ${ }^{\mathrm{a}}$.

downturn (The Economist, March 9, 2002, p. 5). Some industries, such as the advertising industry, are known to be hit particularly hard during contractions. The health-care industry, in contrast, seems to even benefit from unfavorable economic perspectives (Berman and Pfleeger, 1997). Because of this variability, basing one's decision on a common aggregate statistic may well lead to erroneous conclusions (Shama, 1993).

In this paper, we aim to address this gap by introducing various measures to quantify the extent and nature of business-cycle fluctuations in durable sales patterns. Specifically, the notions of cyclical volatility, cyclical comovement and cyclical asymmetry are introduced. We will apply these measures to the sales of a broad set of consumer durables, for which we analyze the cyclical sensitivity in their sales evolution over several decades. Our choice to analyze consumer durables is motivated by the fact that these are expected to be particularly sensitive to cyclical expansions and contractions (Cook, 1999; Katona, 1975).

As a case in point, we present in Figure 1 the over-time US sales of air conditioners. The grey bars in Figure 1 represent the officially registered contractions in the US economy during the observed time period, as identified by the NBER's Business Cycle Dating Committee (www.nber.org/cycles.html), and widely used in many economic studies (see e.g. Christiano and Fitzgerald, 1998; Cogley, 1997). ${ }^{2}$ Figure 1 shows clear evidence of a

2 A contraction, according to the NBER's Business Cycle Dating Committee, is defined as a period of significant decline in economic activity, reflected in a substantial reduction in such variables as total output, income, unemployment, and trade. Specifically, the NBER identifies a month when the economy reaches a peak of activity and a later month when the economy reaches a trough. The time in between is defined as the contraction (www.nber.org/cycles.html). 
strong cyclical influence on durable sales over time. Indeed, almost every time the economy suffers a contraction, sales drop significantly, while expansions are generally associated with increasing industry sales. For instance, during the early 1990s, the contraction caused sales to drop from 4,904 thousand units (in the 1989 peak period) to only 2,481 thousand units at the end of the contraction in 1991. Moreover, during this same contraction, another interesting characteristic is observable. In less than 2 years, air conditioner sales fell to almost half its pre-1990 level, while it took more than 7 years to recover from that loss (the initial peak of 4,904 thousand units was not attained until 1999). Similar patterns can be observed during the contractions of 1973 and 1981. Based on these observations, cyclical fluctuations in durable sales seem to be asymmetric between contractions and expansions: sales clearly drop very fast, compared to a slower upward adjustment in subsequent years. The question then arises whether these observed patterns are idiosyncratic to this specific durable, or whether they reflect a more general characteristic in durable sales evolutions. If so, what is it that causes and explains this asymmetry?

In Figure 2, we add the US sales evolution of clothes dryers, electric washers, freezers, ranges, and refrigerators, and observe a comparable cyclical behavior. Still, it is also apparent from Figure 2 that there is some variation across the different sales patterns. Cyclical sensitivity seems to be more pronounced in air conditioner sales, while freezers and electric washers tend to be less affected. In combination, Figures 1 and 2 provide us with informal evidence on the existence of (i) a strong cyclical sensitivity in durable sales, (ii) asymmetries in up- and downward sales adjustments, and (iii) variability in cyclical sensitivity across durable industries.

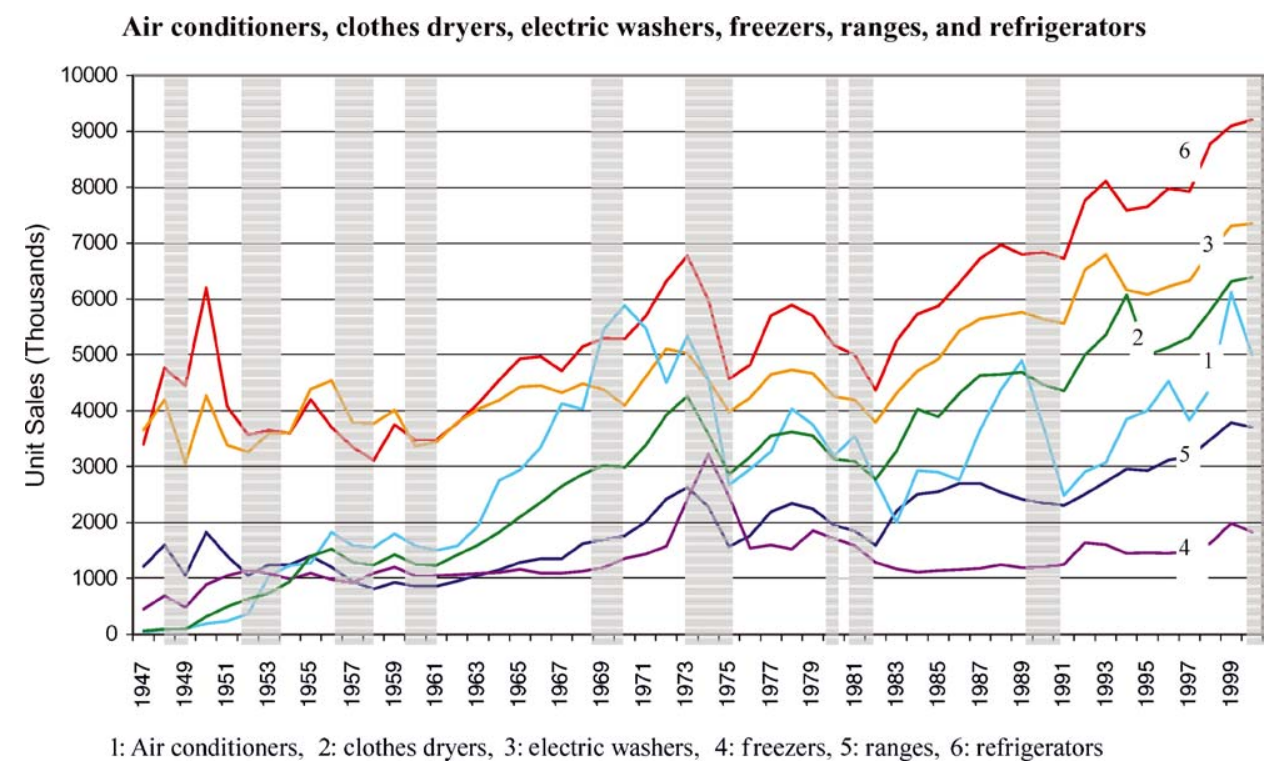

Figure 2. Postwar sales evolution of multiple consumer durables. 
The main purpose of this study is to provide a rigorous analysis of business-cycle fluctuations in durable sales. Even though a number of empirical studies in the economics literature have focused on the relation between aggregate economic fluctuations and total expenditures on consumer durables (e.g. Cook, 1999), our main interest is in this relationship at a more disaggregate, industry level. In particular, we first provide two metrics to quantify the sensitivity of sales (or marketing support) series to business-cycle fluctuations. In addition, we also determine how to best characterize the asymmetry we might observe in this cyclical behavior. To the best of our knowledge, these asymmetry statistics have not been applied at the disaggregate level of individual consumer-good industries. Nor has the variability in cyclical sensitivity across industries and/or firms been linked to various marketing-related drivers. This forms a final contribution of the paper, as we will link the observed cyclical sensitivity to such factors as (among others) industry price reactions, nature of the durable, and expensiveness.

Three key empirical results emerge from our analysis. First, we find that cyclical fluctuations in durable sales are, on average, much more pronounced than in the general economic activity. This calls for a more explicit consideration of cyclical variability in durable sales evolutions than traditional market-response and diffusion models have done. Next, the combined evidence across 24 durables suggests that their sales fall quickly during contractions, while adjusting more slowly during expansions. Finally, industry price volatility, the nature of the price reactions, the type of product, and the stage in the product life cycle are found to moderate the observed extent of cyclical volatility.

The remainder of the paper is organized as follows. In Section 2, we review previous literature, and describe how consumers and companies may respond to business-cycle fluctuations. Next, we introduce the methodology (Section 3), describe the data set (Section 4), and apply the method to a broad set of consumer durables (Section 5), which allows us to derive various Empirical Generalizations (EGs) on durables' business-cycle sensitivity. In Section 6, we introduce a number of variables that may moderate the observed extent of cyclical sensitivity in sales. All results are extensively validated in Section 7. Finally, Section 8 summarizes our main findings, and concludes with suggested areas for future research.

\section{Drivers of cyclical sensitivity}

Cyclical sensitivity in durable sales can be attributed to consumers' typical purchase adjustment decisions for durable goods across up- and downturns, which can be attenuated or reinforced by company reactions. We elaborate on these two drivers of cyclical variability in sections 2.1 and 2.2 respectively.

\subsection{Consumer-related drivers of cyclical sensitivity}

Consumers' actual purchase decisions depend to a considerable extent on their ability to acquire the product, as reflected in their income level (Katona, 1975; Mehra, 2001). Since income developments move in the same direction as developments in the aggregate economy, contractions can decrease consumption through a decline in consumers' wealth (Stock and 
Watson, 1999). Moreover, people's attitude and expectations are found to contribute to cyclical fluctuations, which also explains why the Consumer Sentiment Index has been found to be a good predictor of durable sales (see e.g. Allenby, Jen, and Leone, 1996; Katona, 1975). Thus far, several studies assessed the importance of consumer confidence in the future state of the economy to forecast aggregate durable demand. Adams (1964) was among the first to empirically establish that survey data on the consumers' confidence in the economy contribute significantly to the prediction of consumer expenditures. This conclusion was found for aggregate expenditures on durables, as well as for outlays on automobiles, and durables 'other than automobiles' separately. Similarly, Kamakura and Gessner (1986) study the predictive power of several attitudinal measures on the sales of (i) new cars, (ii) household appliances (including radio and TV), and (iii) family homes. They found that the Consumer Confidence Index and the Buying Intentions Index significantly predict changes in, respectively, sales for new cars and homes beyond objective economic variables such as per capita disposable income or the Consumer Price Index. Kumar, Leone, and Gaskins (1995) provided further empirical support for the contribution of the Consumer Confidence Index in forecasting expenditures on home furnishing, household appliances, refrigerators, and cars. Finally, Allenby, Jen, and Leone (1996) show that the confidence consumers have in the future state of the economy is also a strong predictor of consumer fashion sales. Hence, even if their income remains largely unaffected, mere changes in the consumers' attitude during a contraction can already trigger important reductions in their expenditures. This seems to be especially the case in the context of consumer durables, which are expected to be more vulnerable to business-cycle fluctuations for a number of reasons.

First, consumers who want to restrict their purchases during an economic contraction find it more difficult to cut back on most frequently purchased consumer goods (FPCGs), because these purchases have, in many respects, become habitual. Therefore, consumers' ability to constrain their outlays for FPCGs is limited, while discretionary expenditures on durables are often the first to be reconsidered (Katona, 1975). Second, while expenditures on many non-durables (such as food or clothes) are seen as necessary, expenditures on durables are often outlays of choice. As there is no pressing need to buy these durables at a particular moment in time, consumers can more easily postpone their acquisition when they are confronted with unfavorable economic prospects (Cook, 1999). Third, purchasing a durable can be considered an investment decision on the part of the consumer. Durables often involve more expensive products that are commonly bought on credit; but once obtained, the consumer benefits from the product's utility over an extended period of time (Cook, 1999; Darby, 1972; Horsky, 1990). Peterson and Strongin (1996) emphasized in this respect that because of financial-market imperfections, consumers may find it difficult to borrow and have to rely on internal funding (which is highly procyclical) to finance durable goods. Empirical studies have indeed confirmed that the amount of consumer debt decreases during contractions, supporting the idea that consumers are less able (or willing) to buy durables on credit at that time (Ang, Leong, and Kotler, 2000; Stock and Watson, 1999). Moreover, consumers incur a certain amount of risk and uncertainty, both in terms of the technical reliability of the good and in terms of the benefits they will be able to obtain from it, and these future-oriented considerations are found to be incorporated in their current purchase decisions (Lemon, White, and Winer, 2002; Rust et al., 1999). As such, consumers are more 
inclined to acquire durable goods during favorable economic times. Faced with adverse economic conditions, consumers tend to postpone the acquisition, while current owners of durables may try to lengthen the lives of their product by repairing rather than replacing them (Bayus, 1988; Clark, Freeman, and Hanssens, 1984).

Because of the aforementioned reasons, durable expenditures are expected to be more sensitive to business-cycle fluctuations than other sectors in the economy. Support for this contention, at least at the aggregate level, was found in several macro-economic studies. Already in the '70s and '80s, studies by Barrett and Slovin (1988), Mankiw (1985), and Katona (1975) established that cyclical sensitivity is larger in the context of consumer durables. More recently, Cook (1999) observed that aggregate US expenditures on durables are affected much more severely by economic contractions and expansions than expenditures on non-durables.

A number of studies in this aggregate research tradition explicitly linked the cyclical sensitivity in durable consumption with factors such as uncertainty, interest rates, and credit markets. Barrett and Slovin (1988), for instance, assessed the impact of economic uncertainty on the aggregate demand for consumer durables. They established empirically that the degree of uncertainty consumers face with respect to their disposable income negatively affects total consumer expenditures on durables. For Li and Chang (2004), consumer durables are a form of household investments. Accordingly, the authors highlight the importance of fluctuations in the interest rate, and show, based on simulated data, that changes in the nominal interest rate affect household investments in durables. The link between interest rates and consumer durables is also examined in Mankiw (1985), who concluded that expenditures on durables are far more responsive to changes in the interest rate than non-durables or services. As such, credit markets provide an interesting mechanism to influence household expenditures on durables over the business cycle.

In sum, several studies reported the excessive sensitivity of durable goods at the aggregate level. Still, not all durables need to be affected equally by each of these factors. We may expect, for instance, that more expensive durables are affected especially hard because of their dependence on credit markets. Similarly, the ability to purchase durables may also be reduced by the empirical observation that prices often rise during recessions (Chevalier and Scharfstein, 1996; Taylor, 1999), while Estelami, Lehmann, and Holden (2001) established empirically that consumer price consciousness increases during adverse economic conditions. Previous research evidence therefore suggests that firm and/or industry pricing behavior (which can vary considerably across firms/industries) may affect the cyclical sensitivity of its outcome/sales patterns. For these reasons, we believe that addressing the relation between durables and the business cycle at a more disaggregate level may improve our understanding of durables' cyclical sensitivity, and allow us to further explore why certain durables are affected much harder than others.

Purchase postponement may not only contribute to the existence of cyclical sensitivity, it may also cause the cyclical fluctuations to become asymmetric in nature (Gale, 1996). During contractions, consumers' willingness to buy decreases sharply, as people get a strong incentive to delay their spending and wait for better times (Gale, 1996). Moreover, as consumer wealth is expected to reach its lowest level right after the downturn, it can be expected that consumers postpone their purchases further, even when the economy starts to recover, to take full advantage of the anticipated increase in future income and 
wealth (Caballero, 1993; Gale, 1996). As such, consumers' downward adjustments during contractions tend to occur quickly, while their upward adjustments may be subject to some delay. When this process occurs across many individual decision makers that are all subject to similar market signals, asymmetries are expected to also be present in aggregate sales (Katona, 1975).

Asymmetric adjustments may also arise from the way consumers gain or lose trust (or confidence) in the economic climate. This confidence has been shown to be an important driver of consumers' purchase behavior (see e.g. Allenby, Jen, and Leone, 1996; Kamakura and Gessner, 1986; Kumar, Leone, and Gaskins, 1995). During economic contractions, consumer trust is typically lost very easily. In contrast, research on the development of trust indicates that a breach of trust causes a sustained stretch of doubt among people, so that it may take a longer time to restore it (Holmes and Rempel, 1989; Nooteboom, Berger, and Noorderhaven, 1997). In addition, consumers' negative expectations tend to be prolonged by a tendency to focus primarily on the negative aspects surrounding them, as people seem to interpret information in a way that confirms their pessimistic attitudes or beliefs (Kramer, 2002; Zand, 1972). Accordingly, consumer confidence will only be gradually restored during an expansion. Consumers' attitude changes may therefore contribute to a swift downward sales adjustment during a contraction, and a more gradual increase during economic expansion periods.

Asymmetry in sales may not only manifest itself in a differing speed of adjustment, but also in the extent or level of sales drops versus peaks. Behavioral theories posit that consumers react more extensively to unfavorable changes or losses than to comparable gains (Thaler, 1985; Tversky and Kahneman, 1991). The implications of loss aversion on consumer purchase behavior were initially considered in the context of price changes (see e.g. Krishnamurthi, Mazumdar, and Raj, 1992; Mayhew and Winer, 1992; Putler, 1992). However, other manifestations of asymmetric consumer response include their reaction to product quality changes (Hardie, Johnson, and Fader, 1993), and both expected wage changes (Shea, 1995) and changes in their income level (Bowman, Minehart, and Rabin, 1999). Therefore, when families experience or expect a deterioration in their wage/income, caused by a negative shift in the economy, they are likely to considerably reduce their spending level, while upward adjustments tend to trigger more moderate reactions during business-cycle expansions.

Asymmetries in different phases of the business cycle have long been the object of interest to economists (see e.g. DeLong and Summer, 1986a; Neftçi, 1984; Sichel, 1993). Sichel (1993) distinguishes in this respect between two different types of cyclical asymmetry that could exist either separately or in combination: steepness asymmetry and deepness asymmetry. Our previous discussion offered a behavioral rationale for both phenomena, which are illustrated graphically in Figure 3.

Most previous empirical research has focused on what Sichel labels steepness asymmetry, which refers to cycles where contractions are steeper than expansions. Steepness thus pertains to the speed or rate of change with which an industry (or the economy as a whole) falls into a contraction compared to its speed of recovery. If purchase postponement and trust breakdown indeed slow down the speed of recovery, durable sales should exhibit such asymmetric steepness. On the other hand, deepness asymmetry is defined as the characteristic that troughs are deeper, i.e. further below mean or trend, than peaks are tall. 

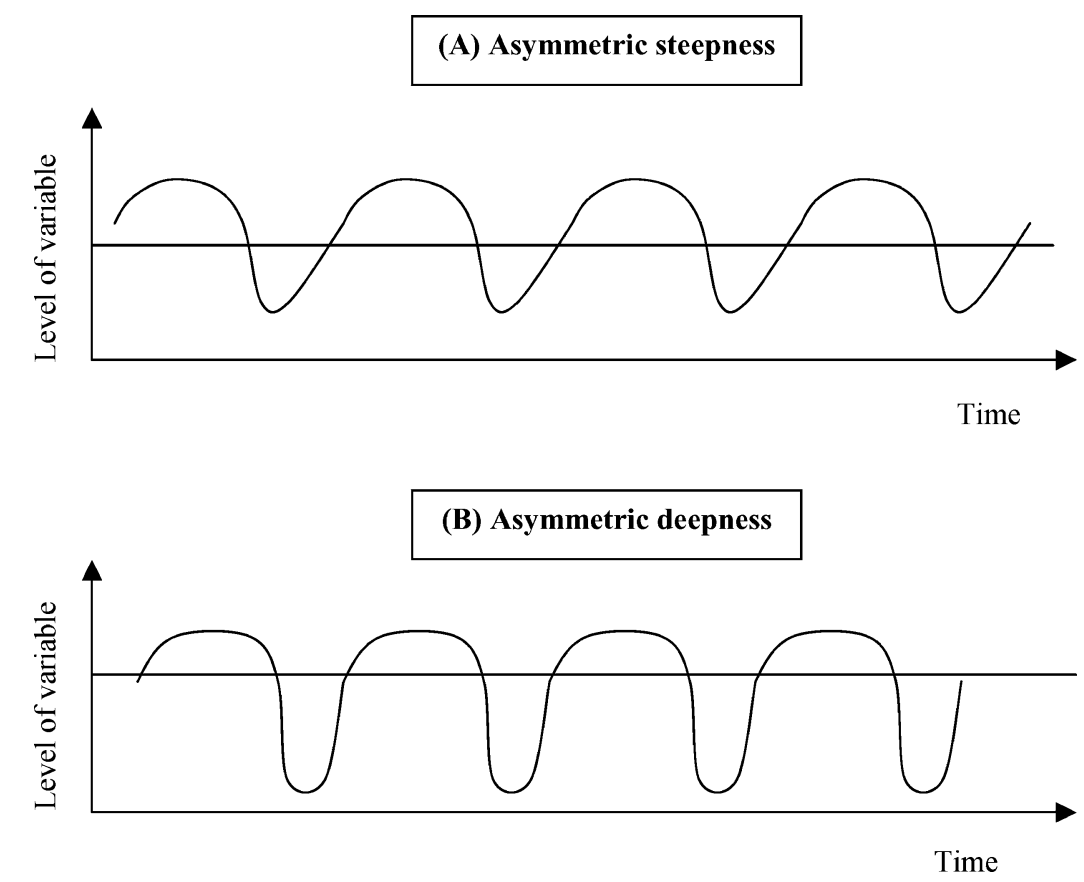

Figure 3. Steepness and deepness asymmetry.

In line with our earlier review on the extent of cyclical sensitivity, a number of aggregate studies have again considered whether or not cyclical asymmetries arise in such series as GNP (DeLong and Summer, 1986a), aggregate consumer expenditures (Holly and Stannett, 1995), and unemployment (Neftçi, 1984; Sichel, 1993), amongst others. Still, no efforts have been made to assess whether such asymmetries may also arise at the more disaggregate, industry level. Insight into such industry-specific asymmetric behaviors is quite relevant, as industries where one or both types of asymmetry are present, will suffer more during contractions than they benefit during expansions: sales will fall faster (steepness asymmetry) and/or further (deepness asymmetry) during contractions than they increase during expansion periods.

\subsection{Firm-related drivers of cyclical sensitivity}

The above patterns may be reinforced or attenuated by the marketing activities of the players in the market. Mascarenhas and Aaker (1989), for example, find evidence that firm strategies differ significantly over business-cycle stages. Companies' main strategic reaction to economic downturns has been documented to be one of cutting costs of all kinds, especially those that do not immediately increase sales revenue (Dobbs, Karakolev, and Malige, 2002). This has been criticized as it may further reduce consumers' propensity to buy during unfavorable economic conditions, and even endanger the company's survival 
potential (The Economist, March 9, 2002, pp. 12-14). Some managers not only reduce budgets, they also tend to reallocate marketing funds to those activities that are prone to generate short-term cash flows. For example, marketing managers have been found to use significantly more coupons and price promotions during contractions to keep their sales up (de Chernatony, Knox, and Chedgey, 1991; Goerne, 1991). So, apart from cutting total marketing budgets during contractions, managers may also redirect budgets to those activities that are better able to generate immediate income.

While this tends to be the dominant reaction pattern, other firms are known to follow an opposite strategy, i.e. to increase their spending, especially on advertising. Empirical evidence exists that companies that view the downturn as an opportunity, and develop aggressive advertising responses to it, can improve their performance, even during the contraction (Dhalla, 1980; Rigby, 2001; Srinivasan, Lilien, and Rangaswamy, 2004). Similarly, a recent PIMS-based study revealed that such firms were not significantly less profitable during contraction periods, while they outperformed their competitors during recovery (Hillier, 1999).

A similar ambiguity exists with respect to the adopted pricing practice. Some have argued that during contractions, prices should move down (Green and Porter, 1984; Tirole, 2001, p. 252), while others have argued the opposite (see e.g. Rotemberg and Saloner, 1986). ${ }^{3}$ Ball and Mankiw (1994), in turn, argue that price rigidity tends to be asymmetric, i.e. prices are more flexible when going up than when going down, which may amplify consumer-related asymmetric sales adjustment.

As indicated in previous sections, business-cycle fluctuations in durable sales patterns can be driven by cyclical adjustments in price (or other marketing-support variables), cyclical fluctuations in consumer confidence, and cyclical fluctuations in income, which cover both consumer-related and firm-related factors. Interestingly, these same factors were identified in Allenby, Jen, and Leone (1996, p. 104) as key components in their Marshallian demand function. Specifically, they specified the quantity demanded $(q)$ as:

$$
q=f(h(p, I), c),
$$

where $h(p, I)$ reflects the objective factors price $(p)$ and income $(I)$, while the subjective factor $c$ reflects the consumers' confidence in the future state of the economy. As each of the right-hand side variables have been shown in our previous discussion to differ across various stages of the business cycle, one can reasonably expect that these fluctuations will also translate (possibly to a varying extent) to the left-hand side performance measure.

\section{Methodology}

Our research methodology consists of two stages: (i) extracting the business-cycle component, and (ii) quantifying the sensitivity of the performance pattern to business-cycle fluctuations.

3 We refer to Section 6 for a more elaborate argumentation on this issue. 


\subsection{Stage 1: Extracting the business-cycle component}

Since firms' reactions to sales fluctuations are heavily dependent on how these are perceived and understood (Dutton and Duncan, 1987), it is crucial for management to know to what extent the sales variations they experience can be attributed to business-cycle fluctuations. Therefore, we first disentangle to what extent over-time fluctuations in sales can be interpreted as business-cycle fluctuations.

In this paper, we adopt the Band-Pass filter formalized in Baxter and King (1999), and applied in Cogley (1997), Mills (2001), and Stock and Watson (1999) among others, to isolate the business-cycle component in each individual series. Based on the observation from many NBER researchers (see e.g. Burns and Mitchell, 1946; Christiano and Fitzgerald, 1998) that US business cycles typically last between 1.5 and 8 years, the underlying idea of the Band-Pass filter is to pass through all components of the time series with periodic fluctuations between 6 and 32 quarters. Given that we will work with annual data (see Section 4), the band-pass filter will admit periodic components between 8 and 32 quarters, rather than between 6 and 32. This is because the 'Nyquist frequency', i.e. the highest frequency about which we have direct information, corresponds to a component of two years in duration when using annual data (see Granger and Hatanaka, 1964; Vilasuso, 1997 for technical details).

The Baxter and King filter originates in the theory of spectral analysis. ${ }^{4}$ Still, the filtering is undertaken entirely in the time domain. We refer to the original study of Baxter and King (1999) for a detailed discussion on both the design of the filter in the frequency domain, and its translation back into the time domain in the form of a symmetric (in terms of leads and lags) moving-average filter. An 'ideal' or optimal band-pass filter would isolate only those components in the series that lie within the specified periodicity range. Such an ideal filter, however, would require an infinite-order moving average, so that in practice an approximation is needed. The proposed approximation is based on a symmetric 3-year centered moving-average transformation, where the weights are chosen to approximate as close as possible the optimal filter. For annual data, this approximate filter can be shown to equal (see Baxter and King, 1999 for details):

$$
c_{t}=0.7741 y_{t}-0.2010\left(y_{t-1}+y_{t+1}\right)-0.1351\left(y_{t-2}+y_{t+2}\right)-0.0510\left(y_{t-3}+y_{t+3}\right),
$$

where $y_{t}$ is the original series in year $t$, and $c_{t}$ the cyclical component to be used in further analyses. ${ }^{5}$

This filter has several appealing features: (i) it extracts the specified range of periodicity, while leaving key properties (such as asymmetries) of the original series unaffected. Sichel (1993, p. 230) already argued that a linear filter (as is the proposed filter) cannot induce

4 See Bronnenberg, Mela, and Boulding (2002) or Parsons and Henry (1972) for marketing applications of the spectral approach to time-series analysis.

5 Note that, because of leads and lags in equation (2), 6 observations are lost in the derivation of the cyclical component. No such loss is incurred in the Hodrick-Prescott (HP)-filter introduced in Section 7 to validate our findings. 
non-linearities such as asymmetries in a filtered series if they were not present to begin with. Moreover, Baxter and King (1999, p. 575) show that a moving average filter with symmetric weights on leads and lags will leave the properties we are interested in unaffected. As such, the filter we propose is particularly well-suited to test for asymmetries in the series; (ii) it does not introduce a phase shift, in that it does not alter the timing of the cycles, so that contraction and expansion dates in the filtered series correspond to the same dates as in the original series; (iii) it removes unit roots up to the second order, and eliminates quadratic deterministic trends (Baxter and King, 1999). The latter property is especially relevant in our study. Indeed, according to the product-life-cycle hypothesis, product sales go through distinct stages, and modeling a category's sales evolution from onset, over maturity, and into eventual decline often requires the inclusion of a higher (likely second) order deterministic or stochastic trend (Franses, 1994). In addition, earlier research confirms that sales series often contain a unit root, while the likelihood of finding non-stationarity increases when the considered sample period becomes longer (Dekimpe and Hanssens, 1995b). In this study, we consider sales patterns over multiple decades, which makes a filtering procedure that can properly handle unit root series more appealing; (iv) finally, the method is operational and easy to implement, thereby satisfying an important decision-calculus criterion (Little, 1970).

Even though this specific filter has been used extensively in the (macro)-economic literature (see e.g. Baxter and King, 1999; Cogley, 1997; Stock and Watson, 1999; Vilasuso, 1997), one should keep in mind that every filter involves some subjectivity. We will therefore validate our substantive conclusions by also implementing another procedure frequently used to isolate the cyclical component, i.e. the Hodrick and Prescott (HP)-filter (Hodrick and Prescott, 1997) (see Section 7 for details).

In the second stage, four summary statistics are derived from the cyclical component $\left(c_{t}\right)$ isolated in Stage 1. They parsimoniously describe the extent and nature of the cyclical sensitivity in a given series. Specifically, we consider the extent of cyclical volatility and cyclical comovement (Stage 2a), and examine the two aforementioned kinds of cyclical asymmetry (Stage $2 b$ ): deepness and steepness asymmetry.

\subsection{Stage 2a: Quantifying the extent of cyclical sensitivity}

To quantify the extent or severeness of the cyclical variations, we (i) look at the durables' cyclical variability (volatility), and (ii) examine their degree of cyclical comovement with the general economic activity. Cyclical variability is quantified through the standard deviation of the isolated cyclical component $\sigma(c)$ (see e.g. Hodrick and Prescott, 1997; DeLong and Summer, 1986b for a similar operationalization). Since these standard deviations are comparable across series only when the series have the same unit, we analyze the series in logarithms, so that the units (when multiplied by 100) represent percentage deviations from the series' growth path (Stock and Watson, 1999, p. 29).

Cyclical volatility focuses on the size of the ups and downs at business-cycle periodicities, but is not concerned with the synchronized nature of this pattern with the overall economic cycle. This property is captured through the notion of cyclical comovement, which measures the extent to which business-cycle fluctuations in the economy as a whole translate into 
cyclical fluctuations in a specific durable's sales performance. We can operationalize the concept by regressing the cyclical component of the durable series $\left(c_{i, t}\right)$ on the cyclical component in real GNP $\left(c_{i, t}^{\mathrm{GNP}}\right)$ (this approach is conceptually similar to Stock and Watson (1999), who use $\operatorname{corr}\left(c_{i, t}, c_{i, t}^{\mathrm{GNP}}\right)$ as comovement statistic). ${ }^{6}$

$$
c_{i, t}=\alpha_{i}+\beta_{i} c_{i, t}^{\mathrm{GNP}}+\varepsilon_{i, t}
$$

Although the business cycle technically is defined through a comovement across many sectors in the economy, fluctuations in aggregate output are at the core of the business cycle, and the cyclical component of GNP is therefore a useful proxy for the overall business cycle. ${ }^{7}$ Note also that because of the nature of equation (3), i.e. both $c_{i, t}$ and $c_{i, t}^{\mathrm{GNP}}$ represent percentage deviations, $\beta_{i}$ can be interpreted as an elasticity, making the comovement measure comparable across different industries.

This elasticity, however, only looks at the instantaneous effect, while potential dynamic influences are ignored. To account for these dynamics, we will derive a dynamic comovement elasticity that also allows for one-year lead and lag effects. This time interval is in line with the cyclical cross-correlations reported in Stock and Watson (1999, Tables 2 and 3). By directly including lead and lagged variables for $c_{i, t}^{\mathrm{GNP}}$ into equation (3), the model becomes:

$$
c_{i, t}=\alpha_{i}+\sum_{k=-K}^{K} \beta_{i, k} c_{i, t-k}^{\mathrm{GNP}}+\varepsilon_{i, t}
$$

with ' $K$ ' the number of dynamics accounted for. ${ }^{8}$ For each of the durables, a dynamic comovement elasticity can be calculated, following the procedure advocated in Van Heerde (1999) or Macé and Neslin (2004), as $\beta_{i}^{K}=\sum_{-K}^{K} \beta_{i, k}$. In subsequent sections, we will report on this dynamic comovement elasticity. The results obtained through the static comovement statistic were very comparable, however, and are available from the authors upon request.

Although both statistics (volatility and comovement) describe the extent of businesscycle sensitivity in durable industries, they approach cyclical sensitivity from a distinct,

6 We regressed the cyclical component of the durable on the cyclical component of GNP over the corresponding time period, and added a durable-specific subscript $i$ to $c_{i, t}^{\mathrm{GNP}}$ to indicate differences in sample length.

7 One might argue that one should be careful when correlating business cycles (as reflected in the cyclical fluctuations of GNP) with cyclical fluctuations extracted from durable sales, as durables represent part of GNP itself (we thank an anonymous reviewer for bringing this to our attention). Still, in the context of this study, this is not a major concern for the following reasons. First, expenditures on consumer durables in the US represent only a small part of total GNP (about $9 \%$ according to Barrett and Slovin (1988)), and from this part (9\%), only 24 consumer durables are involved in the current analyses. They represent, on average, $8 \%$ of the total outlays spent on durables in the US over the last 54 years (see Section 6, pp. 21-22). Combined, the 24 durables constitute only $0.72 \%$ of US GNP, and for this reason, they are unlikely to drive the bulk of the total variation in the economy. Second, Christiano and Fitzgerald (1998, p. 62) illustrated, using a numerical example, how this problem of 'natural' correlation becomes less of a problem as GNP is made up of more sectors in the economy. Indeed, assuming only 33 independent sectors as identified by Christiano and Fitzgerald (1998), the natural correlation can be shown to be less than 0.2 . Put differently, with many different sectors in the economy, the 'natural' correlation or correlation 'by construction' is negligible.

8 For yearly data, $K=1$; for quarterly data, $K=4$. 
yet complementary, perspective. Cyclical volatility $(\sigma(c))$ is a univariate concept, and measures the size of the deviations from the series' growth path occurring at business-cycle periodicities. This statistic is always positive $(\geq 0)$, and larger values indicate a larger degree of variability in the cyclical component of the series. The extent of cyclical variability within a series, however, is not fully informative on how these fluctuations relate to the overall economic activity, a key-defining characteristic of the business cycle (Christiano and Fitzgerald, 1998). Indeed, large (univariate) cyclical swings may be either procyclical (when changes occur in the same direction as the aggregate economy) or countercyclical (in case movements are in the opposite direction). Also, univariate variability does not reflect the extent to which a durable's cyclical fluctuations tend to move together with the ones in more general economic indicators. The comovement elasticity, in contrast, quantifies both the sign of this relationship, and the extent to which overall economic expansions and contractions translate into attenuated $\left(\left|\beta_{i}^{K}\right|<1\right)$ or amplified $\left(\left|\beta_{i}^{K}\right|>1\right)$ cyclical swings in the sales of a specific durable.

\section{3. $\quad$ Stage $2 b$ : Identification of cyclical asymmetries}

Following the pioneering work of Sichel (1993), we derive cyclical (a)symmetries based on the third-order moment, i.e. the skewness statistic, of the filtered series. First, if a time series exhibits deepness asymmetry, it should exhibit negative skewness relative to the mean or trend, indicating that it should have (i) fewer observations below its mean or trend, with (ii) a larger (absolute) average value compared to the observations above. Such behavior is illustrated in Figure 3, panel B. To construct a formal test for deepness asymmetry, the following coefficient of skewness is computed:

$$
D\left(c_{t}\right)=\frac{\left[T^{-1} \sum_{t=1}^{T}\left(c_{t}-\bar{c}\right)^{3}\right]}{\sigma(c)^{3}},
$$

where $\bar{c}$ is the mean of the cyclical component $c_{t}, \sigma(c)$ its standard deviation, and $T$ the sample size (Sichel, 1993).

Second, if a time series exhibits steepness asymmetry, its first difference, representing the slope or rate of change, should exhibit negative skewness. As such, decreases in the series corresponding to contractions should be larger, but less frequent, than the more moderate increases during expansions. We refer to Figure 3 (panel A) for a graphical illustration of this behavior. The formal test statistic for steepness asymmetry is based on the coefficient of skewness for $\Delta c_{t}$, the first difference of the cyclical component:

$$
S T\left(\Delta c_{t}\right)=\frac{\left[T^{-1} \sum_{t=1}^{T}\left(\Delta c_{t}-\overline{\Delta c}\right)^{3}\right]}{\sigma(\Delta c)^{3}},
$$


where $\overline{\Delta c}$ and $\sigma(\Delta c)$ are, respectively, the mean and standard deviation of $\Delta c_{t}$ (Sichel, 1993). ${ }^{9}$

\section{Data}

The data involve postwar annual US time series of unit sales for 24 consumer durables. Sales patterns for some of these durables were already presented in Figures 1 and 2. As illustrated in Table 1, the durables cover a wide range of household appliances such as blenders, dishwashers and steam irons, while also including leisure goods such as (color and black \& white) TVs.

The data span several decades, ranging between 16 (1972-1987) years for calculators and 54 (1947-2000) years for durables such as ranges, refrigerators and electric washers, with an average (median) duration of 39 (39) years. Based on US national statistics from the NBER (www.nber.org/cycles.html), the postwar data period considered was characterized by 10 complete business cycles, with an average duration of about 5 years; the longest recorded cycle being $10 \frac{1}{2}$ years. As such, all durables analyzed cover multiple business cycles. From Table 1, it can also be seen that there were a number of new introductions across the sample period; the current data therefore offer a mix of both more recent and more established durables, which can be expected to be in different stages of their life cycle (earliest introduction $=1908$; latest introduction $=1972$ ).

The data reflect total sales at the product-category level, and therefore comprise both trial and replacement purchases. Accordingly, for durables introduced earlier, replacements are likely to make up a larger portion of their current sales, and to constitute a major part of the total durable performance (Bayus, 1988; Steffens, 2001).

In addition to unit sales data, sales were also available in retail value (\$ sales), which allowed us to derive over-time unit prices. These prices were adjusted for inflation using the US Consumer Price Index (CPI). ${ }^{10}$ As can be seen in Table 1, the 24 durables exhibit considerable variability in terms of average prices (most expensive durable $=$ color TVs $(\$ 821)$; least expensive durable $=$ corn popper $(\$ 24)$ ).

Real GNP is a good proxy for overall economic activity, and thus a useful benchmark for comparisons across multiple series (DeLong and Summer, 1986b). ${ }^{11}$ As such, the same summary statistics introduced in Section 3 will be used to assess the cyclical sensitivity of US postwar real GNP. Data on annual US real GNP (1947-2000), measuring the nation's

9 To determine the significance of both test statistics, asymptotic standard errors are derived as follows. For deepness asymmetry, we regress $z_{t}=\left(c_{t}-\bar{c}\right)^{3} / \sigma(c)^{3}$ on a constant, the significance of which corresponds to the significance of $D\left(c_{t}\right)$. Indeed, the coefficient estimate associated with the constant equals the deepness statistic, and the corresponding standard error measures its statistical reliability. Since the observations on $c_{t}$ are serially correlated, the correction suggested by Newey and West (1987) is implemented in the derivation of the standard errors. Asymptotic, Newey-West corrected, standard errors for the steepness statistic can be calculated using a similar procedure, but with $z_{t}=\left(\Delta c_{t}-\overline{\Delta c}\right)^{3} / \sigma(\Delta c)^{3}$.

10 Source: US Census Bureau, Statistical Abstract of the United States: 2001.

11 Obviously, one could use other macro-economic indicators such as national income (Nicosia, 1974), disposable income (Chowdhury, 1994), savings (Taylor and Weiserbs, 1972), interest rates (Mankiw, 1985) or the Index of Consumer Confidence (Allenby, Jen, and Leone, 1996) as benchmark. However, real GNP is typically considered to be a very good proxy for the overall economic activity (DeLong and Summer, 1986b). 
Table 1. Description of the dataset.

\begin{tabular}{|c|c|c|c|c|}
\hline Category & Years studied & Launch year ${ }^{\mathrm{a}}$ & Average price (in \$) & Price range (in \$) \\
\hline Range & $1947-2000$ & 1908 & 657 & $338-1022$ \\
\hline Refrigerator & $1947-2000$ & 1914 & 819 & $479-1190$ \\
\hline Vacuum cleaner & 1947-1984 & 1911 & 240 & $148-355$ \\
\hline Electric washer & $1947-2000$ & 1921 & 614 & $265-885$ \\
\hline Air conditioner & $1947-2000$ & 1934 & 728 & 236-2044 \\
\hline Black \& white TV & $1947-2000$ & 1946 & 429 & $33-2039$ \\
\hline Freezer & 1947-2000 & 1935 & 767 & $231-1487$ \\
\hline Electric bed cover & 1947-1980 & 1940 & 82 & 37-191 \\
\hline Clothes dryer & $1947-2000$ & 1937 & 545 & $221-960$ \\
\hline Dishwasher & $1947-2000$ & 1940 & 651 & $265-1198$ \\
\hline Disposer & $1947-2000$ & 1938 & 230 & $72-563$ \\
\hline Steam iron & 1947-1985 & 1938 & 52 & $30-76$ \\
\hline Blender & 1948-1985 & 1937 & 83 & $22-157$ \\
\hline Built-in range & 1954-2000 & 1953 & 588 & $349-1070$ \\
\hline Corn popper & 1954-1985 & $?$ & 24 & $17-34$ \\
\hline Can opener & $1958-1985$ & 1956 & 36 & $16-91$ \\
\hline Color TV & 1960-2000 & 1954 & 821 & 146-2206 \\
\hline Oral hygiene device & $1963-1985$ & 1955 & 34 & $20-62$ \\
\hline Electric knife & 1964-1985 & $?$ & 38 & $19-82$ \\
\hline Water pulsator & 1966-1985 & 1966 & 39 & 24-107 \\
\hline Hair setter & 1968-1985 & $?$ & 38 & $24-69$ \\
\hline Microwave oven & 1970-2000 & 1967 & 545 & $165-1282$ \\
\hline Trash compactor & 1971-2000 & $?$ & 337 & $216-639$ \\
\hline Calculator & 1972-1987 & 1972 & 100 & $21-508$ \\
\hline
\end{tabular}

${ }^{\mathrm{a}}$ Details on the specific operationalization of this variable are given in measurement Appendix A.

general economic activity, was obtained from the US Census Bureau (Statistical Abstract of the United States: 2001).

\section{Empirical results}

Business-cycle sensitivity was argued to manifest itself in the extent of cyclical variations, as reflected in (i) cyclical volatility and (ii) cyclical comovement (Section 5.1), as well as in the presence of one or both types of cyclical asymmetry (Section 5.2). First, we discuss the main results related to cyclical volatility in durable sales. Comparing these results with the cyclical volatility in GNP gives an indication as to whether durable goods are more or less sensitive to business cycles than the general economic activity. Next, we report on the extent to which durables move along with the aggregate cycles, as reflected in 
their cyclical comovement. As indicated before, the extent of cyclical volatility and their level of comovement with GNP are derived on log-transformed data to obtain comparable units across the various series of interest (see Stock and Watson, 1999, for a similar practice). Finally, we assess both types of cyclical asymmetry, which were argued in Section 2 to reflect consumers' purchase adjustment decisions for durables across economic up- and downturns, and which could be amplified/attenuated by the firms' marketing actions.

\subsection{Quantifying the extent of cyclical sensitivity}

The key findings related to the extent of cyclical sensitivity (volatility and comovement) are summarized in Table 2.

A first substantive conclusion is that consumer durables are affected more by businesscycle fluctuations than the overall economic activity, reflected in real GNP. Based on the ratio of an individual durable's cyclical volatility to the cyclical volatility in GNP, i.e. $\sigma\left(c_{i}\right) / \sigma\left(c_{i}^{\mathrm{GNP}}\right)$, we find that in only one out of 24 cases (calculators), durables have a ratio smaller than 1 , meaning that in only one case the cyclical volatility is smaller than the one observed in GNP over the corresponding time horizon. Focusing on the volatility across all 24 durables, we find an average value of $0.091(9.1 \%)$, ranging from 0.017 (1.7\%) for calculators to $0.162(16.2 \%)$ for black \& white TV. In contrast, cyclical volatility in postwar real GNP is, on average, only 0.021. Durables are therefore, in terms of their cyclical volatility, more than four times as sensitive to business-cycle fluctuations than the general economic activity. This calls for a more explicit consideration of the cyclical variability in the sales evolution of consumer durables in both market response and diffusion models. As for the former, two recent surveys (Hanssens, Parsons, and Schultz, 2001; Leeflang et al., 2000) do not report on any study which explicitly considers business-cycle fluctuations when analyzing sales patterns. A similar observation applies in the context of diffusion

Table 2. Results on the extent of cyclical sensitivity.

\begin{tabular}{lccc}
\hline & Average size (median) & Range & No. of durables $>1$ \\
\hline $\begin{array}{l}\text { Cyclical volatility } \\
\text { Durables }\end{array}$ & $0.091(0.096)$ & $0.017-0.162$ & $23^{\mathrm{b}}$ \\
GNP & $0.021(0.020)$ & $0.019-0.028^{\mathrm{a}}$ & $\mathrm{NA}^{\mathrm{c}}$ \\
Comovement & & & $19^{\mathrm{d}}$ \\
$\beta_{i}^{K}$ & $2.250(2.253)$ & $-0.268-4.969$ & \\
\hline
\end{tabular}

${ }^{\text {a }}$ Since the volatility for the respective durables was derived over different time periods, we assessed the volatility in GNP over the corresponding sample periods. The range in GNP thus reflects the difference in the stability of the economy across different time periods.

${ }^{\mathrm{b}}$ Represents the number of durables where the ratio of an individual durable's cyclical volatility to the cyclical volatility in GNP, over the corresponding sample periods, is larger than 1 .

${ }^{\mathrm{c}} \mathrm{NA}=$ Not applicable.

${ }^{\mathrm{d}}$ Represents the number of durables with a dynamic comovement elasticity in excess of 1 . 
models, where neither Mahajan, Muller, and Bass (1990) nor Rogers (1983) identify any study which accounts for a durable's excessive business-cycle sensitivity. ${ }^{12}$

Business-cycle fluctuations in durable sales move closely together with the aggregate cycle. Based on equation (4), we find that all durables except two (calculators and freezers) have a positive $\beta_{i}^{K}$-elasticity, meaning that economic contractions (expansions) cause durable sales to drop (rise). In addition, the overall degree of comovement is high, as most durables (19) have a dynamic comovement elasticity larger than 1, implying that general business-cycle swings get amplified in the context of durable sales. The average degree of comovement between durable goods and the business-cycle component in GNP, as measured by the average $\beta_{i}^{K}$, is 2.250 , ranging between -0.268 (freezers) and 4.969 (trash compactors). This again confirms that, compared to GNP, durables are affected much harder during contractions.

Although cyclical volatility and comovement focus on business-cycle sensitivity from a different point of view, we do find that, for durable industries, results from both statistics are fairly congruent: the correlation between both summary statistics is a positive and significant $0.52(p<0.01)$.

\subsection{Identification of cyclical asymmetries}

Based on the skewness analyses, we find that only five of the 24 (log-transformed) series (a mere $21 \%$ ) have the expected negative sign for the deepness statistic, and in none of these five cases did the statistic turn out to be significant. The deepness statistic also exhibits a positive average value of 0.43 . Therefore, our results indicate that there is little, if any, evidence of deepness asymmetry in durable sales. Steepness asymmetry, on the other hand, is found to be more prevalent: 18 out of 24 series $(75 \%)$ have the expected negative sign for the steepness statistic, and also the average value for asymmetric steepness is negative $(-0.39)$. However, for only one durable (steam irons), the steepness statistic was found to be significant at a $10 \%$ significance level.

Even though the log-transform is called for when deriving the extent of cyclical sensitivity, it may distort one's inferences about the (a)symmetric nature of a given time series (see e.g. Ruppert and Aldershof, 1989). ${ }^{13}$ However, comparable results were obtained when testing for asymmetries on the original (non-transformed) data: few series (seven) have a negative sign for the deepness statistic, and the average value for the deepness statistic is 0.45 . In contrast, 20 out of 24 series did have the expected negative value for the steepness statistic, resulting in a mean value of -0.40 . None of the individual cases was significant at conventional significance levels.

12 International studies on the diffusion of consumer durables have occasionally accounted for the different countries' macro-conditions, as reflected in their GNP/capita, urbanization rate, etc. (see e.g. Dekimpe, Parker, and Sarvary, 2000; Helsen, Jedidi, and DeSarbo, 1993). With the exception of Van den Bulte (2000), only cross-sectional variation along those dimensions was considered, in that only information on a single year (Dekimpe, Parker, and Sarvary, 2000) or the average across a number of years (Helsen, Jedidi, and DeSarbo, 1993) was used. The over-time variation in these macro-conditions, however, was still ignored.

13 To avoid this potential distortion, we will report on the (a)symmetric nature of the original series in both the meta-analytic and validation exercises. 
As it has been argued that the power of each of the individual skewness tests tends to be rather low (see e.g. Mills, 2001; Razzak, 2001; Verbrugge, 1997), especially when working with annual data, we conducted a meta-analysis to derive the combined evidence of cyclical asymmetry across all 24 durables. To do so, we used the one-sided $p$-values associated with the deepness and steepness statistic, applying the method of adding weighted $Z$ 's (Rosenthal, 1991). This should offer a stronger test for the presence of cyclical asymmetries than the individual impact estimates.

The meta-analysis confirmed the absence of any deepness asymmetry in the sales evolution of the consumer durables at hand $(p=0.96)$. For steepness asymmetry, on the other hand, the collective, meta-analytic result indicated significant evidence of steepness, with the null hypothesis of symmetry rejected at a $\%$ significance level $(p=0.03)$. These results suggest that expenditures on consumer durables will not necessarily fall more extensively, even though they will do so faster, during contractions than they increase during expansionary periods. This observation is consistent with the general prediction that households tend to postpone durables' acquisition in response to negative wealth shocks (Caballero, 1993; Clark, Freeman, and Hanssens, 1984; Cook, 1999), and corroborate Gale's (1996) theoretical finding that purchase postponement causes sluggish adjustment. ${ }^{14}$

\section{Moderator analyses}

Our earlier results found durable sales to be affected to a much larger extent by businesscycle fluctuations than the general economic activity. It is interesting to note, though, that there exists quite some variation in this cyclical sensitivity across the 24 durables studied (see Table 2; range cyclical volatility $=0.017-0.162$; range cyclical comovement $=-0.268-$ 4.969). Analyzing this cross-sectional variation in cyclical volatility and comovement can provide us with additional insights into how and why buying patterns for durables are altered in response to aggregate economic fluctuations. We do not perform a second-stage analysis on the asymmetry statistics because, individually, almost none of the durables experienced significant deepness or steepness asymmetry. In addition, a formal chi-square homogeneity test (Rosenthal, 1991) revealed that there was not enough variation present in the effect sizes of deepness and steepness to be further explored (i.e. no significant heterogeneity is found among the 24 deepness $\left(\chi^{2}(23)=6.09 ; p=0.99\right)$ and steepness $\left(\chi^{2}(23)=4.22 ; p=0.99\right)$ statistics $)$.

To that extent, we will explore in subsequent analyses the relationship between the observed extent of cyclical sensitivity (reflected in cyclical volatility and comovement) and (i) industry price reactions, (ii) the extent of price stability, (iii) the product's expensiveness, (iv) the nature of the durable (convenience vs. leisure), (v) the state of the economy during launch, and (vi) the importance of replacement buying. First, we provide some prior

14 As for GNP, we find no evidence of asymmetry, with average values for the deepness (mean $D\left(c_{t}\right)=-0.06$ ), and steepness (mean $\mathrm{ST}\left(c_{t}\right)=-0.18$ ) statistics approximating a perfectly symmetric distribution (where skewness $=0$ ). DeLong and Summer (1986a) as well as Sichel (1993) also failed to detect any evidence of steepness asymmetry in US GNP, while Sichel found very weak evidence of deepness asymmetry in (quarterly) postwar GNP. 
expectations as to the expected sign of these relationships, followed by a description of the adopted testing procedures, and a discussion of the empirical findings. We refer to measurement Appendix A for a discussion on the specific operationalization that was adopted for each of the constructs.

\subsection{Prior expectations}

Industry price reaction. Industry price reactions to business-cycle fluctuations can either reinforce or attenuate cyclical sensitivity in sales by, respectively, increasing or decreasing prices during contractions. To structure our discussion, we first consider the direction of price changes during contractions, after which we assess the impact of such price reactions on the extent of cyclical sensitivity observed in durable sales patterns.

Normative arguments on the nature of price changes during a contraction have been made in both directions. The established view in the industrial-organization literature is based on the work by Green and Porter (1984), who show that lower prices should occur when demand is unexpectedly low. Firms then switch from collusive, high prices to lower, competitive prices because they attribute the lower profits (caused by lower demand) to cheating on the part of their rivals (Green and Porter, 1984; Tirole, 2001, p. 252). Rotemberg and Saloner (1986) challenged this view, and argued that, especially during high-demand periods (booms), it is more beneficial to undercut on the high collusive price, implying that collusion will be less likely to be sustained. This leads to lower competitive prices during expansions and higher collusive prices during contractions. Moreover, Marn, Roegner, and Zawada (2003) argue that increasing prices $(p)$ during a contraction allows companies to offset revenue losses $(p . q)$ caused by reduced sales $(q)$ levels. Chevalier and Scharfstein (1996) stress that credit market imperfection may prevent companies from choosing the prices that, according to normative theory, would maximise profits. They show that during contractions, financially-constrained firms raise prices relatively more than less-financially constrained firms. Empirical analyses on the issue predominantly support the existence of higher prices during contractions (conform Rotemberg and Saloner's view) (see e.g. Backus and Kehoe, 1992; Rotemberg and Saloner, 1986; Rotemberg and Woodford, 1999).

The direction of price changes may, in turn, influence the extent of business-cycle fluctuations in durable sales patterns. Increasing prices during contractions can be expected to further reduce consumers' propensity to buy durables at that time, suggesting that industries tend to enhance cyclical sensitivity in their performance (Frantzen, 1986).

Industry price stability. Bishop, Graham, and Jones (1984) underscore the importance of a flexible pricing system to quickly and adequately respond to changing market conditions such as economic contractions, so that swings in performance can be reduced. Industries where prices are more flexible, as reflected in a higher over-time price variability, can more easily implement price adjustments in response to economic fluctuations. A rigid pricing practice is expected to further reduce output during contractions, and to amplify cyclical swings in durable sales (Frantzen, 1986).

Expensiveness. For more expensive durables that represent an important share of the household budget, consumers' relative willingness and ability to pay decreases more substantially during contractions due to the shrinking of their income (Horsky, 1990). Indeed, 
such a purchase would put a more severe burden on the family in already unfavorable economic conditions. Households are therefore expected to refrain sooner from buying expensive durables during contractions than they do for less expensive ones (Cook, 1999). Still, one could argue that households have the opportunity to borrow in order to smooth income fluctuations. Mankiw (1985), for instance, established empirically that durables are far more sensitive to changes in real interest rates than non-durables. However, because of earlier debt accumulation, some families will find it difficult to borrow during an economic contraction when their financial situation is likely to worsen even further. In addition, real interest rates are (weakly) countercyclical (Stock and Watson, 1999), meaning that financing durables becomes relatively more expensive during contractions. The resulting amount of debt outstanding by US consumers evolves procyclical, supporting the idea that during the contraction, consumers are less able and/or willing to buy expensive durables on credit (Ang, Leong, and Kotler, 2000; Stock and Watson, 1999, Table 2). This may further amplify cyclical fluctuations in durable sales.

Type of product. Time-saving convenience goods may be less sensitive to economic fluctuations than leisure durables, because they more easily become a necessity for the consumer, as they can substitute for otherwise labor-intensive household activities (Horsky, 1990; Parker, 1992; Tellis, Stremersch, and Yin, 2003).

State of the economy during launch. Devinney (1990) and Clark, Freeman, and Hanssens (1984) argue that it would be unwise to introduce new durables during an economic contraction unless the product is truly superior, so that consumers are willing to buy it even during an economic contraction. We will test whether any initial superiority is able to protect the durable in subsequent periods, causing a reduced cyclical sensitivity.

Importance of replacement buying. Replacement purchases occur not only because of product failure. Durables may also be replaced for other reasons, such as the availability of new and/or improved features, or changing styles, tastes and fashion (Bayus, 1988; Steffens, 2001). This suggests that consumers tend to be quite flexible in changing the timing of a replacement purchase. When faced with worsening economic conditions, owners of durables can be expected to prolong the lives of their existing products, and hence to postpone their replacement. Therefore, replacement purchases where product failure is not the key driver of the replacement decision can be argued to be more sensitive to cyclical variation than trial purchases. On the other hand, accustomization may cause replacement purchases to be less sensitive to business-cycle fluctuations than trial purchases. Consumers may become habituated to the durables they currently own, in which case adverse economic conditions become less likely to prevent them from replacing the goods in case of product failure (Kamakura and Balasubramanian, 1987). Moreover, the considerable risk associated with trial purchases may induce consumers to delay an initial acquisition during economic contractions, which could cause business-cycle fluctuations to be more pronounced in trial purchases (Parker and Neelameghan, 1997).

\subsection{Testing procedure and empirical findings}

To determine the direction of price changes during economic contractions, we regress the cyclical component in each durable's price $\left(c_{i, t}^{P}\right)$ on the cyclical component of 
total US expenditures on durables ( $c_{t}^{\text {TOTDUR }}$, an aggregate series covering the expenditures on all consumer durables in the US, as published by the Bureau of Economic Analysis (www.bea.doc.gov). Total US expenditures on durables (which encompasses much more than even the combined sales of our 24 durables) was used rather than a given durable's sales pattern to avoid potential endogeneity problems. Indeed, the 24 durables included in our study represent only $8 \%$ of the total outlays spent on consumer durables by US households over the last 54 years (with a range from 0.8 to $19 \%$ across the different years). The following equation is estimated for each of the 24 durables:

$$
c_{i, t}^{P}=\gamma_{i}+\delta_{i} c_{t}^{\mathrm{TOTDUR}}+\eta_{i, t},
$$

for $t=1, \ldots, T_{i}$, with $T_{i}$ the sample size (number of observations) for durable $i .24$ such regressions are estimated, after which a meta-analysis is performed on the $\hat{\delta}_{i}$ to quantify the overall direction of price changes across industries. A negative $\delta_{i}$-value in equation (7) is consistent with a price increase during contraction periods. In line with previous empirical research (see e.g. Backus and Kehoe, 1992; Rotemberg and Woodford, 1999), most durable industries indeed seem to increase prices during an economic contraction, while decreasing prices during an expansion. For 19 out of 24 durables, $\hat{\delta}_{i}$ was negative, and the subsequent meta-analysis on the combined significance of a negative price reaction indicated strong support for a consistent negative $\delta$ across all durables $(p=0.01)$.

Such countercyclical pricing is likely to induce an enhanced cyclical sensitivity in durable sales. To test this conjecture, we include the estimated $\hat{\delta}_{i}$ as an explanatory variable in a regression framework, and determine if industries that price more countercyclical (more negative $\delta_{i}$ ) are indeed characterised by a higher degree of cyclical sensitivity.

The impact of these industry price reactions on the extent of cyclical sensitivity, along with the impact of price stability, expensiveness and nature of the durable, is derived by regressing $\sigma\left(c_{i}\right) / \sigma\left(c_{i}^{\mathrm{GNP}}\right)$ (relative cyclical volatility) and $\beta_{i}^{K}$ (comovement elasticity) against, respectively, $\hat{\delta}_{i}$ (as estimated in equation (7)), PRice VOLatility, EXPENSiveness and product TYPE. We use the relative cyclical volatility as dependent variable since $\sigma\left(c_{i}\right)$ is obtained for individual durables across different time periods. Accordingly, to control for the potential confounding impact of the overall economic stability, $\sigma\left(c_{i}\right)$ is divided by $\sigma\left(c_{i}^{\mathrm{GNP}}\right)$, the cyclical volatility of GNP over the corresponding period.

Furthermore, Clark, Freeman, and Hanssens (1984) pointed out that several consumer durables are tied to the consumers' decision to buy a house. To control for the resulting complementarities, we add a 'new-housing elasticity' variable (HOUSE $\left.E_{i}\right)$ in subsequent regressions. This control variable is operationalized as the sum of the instantaneous and one-year lagged effect from an auxiliary regression of the cyclical component of the durable sales patterns on the (instantaneous and lagged) cyclical fluctuations in a series containing the (log-transformed) total new privately-owned housing units started in the US (source: 
www.census.gov). ${ }^{15}$ This results in the following test equation:

$$
\begin{aligned}
& {\left[\begin{array}{c}
\sigma\left(c_{i}\right) / \sigma\left(c_{i}^{\mathrm{GNP}}\right) \\
\beta_{i}^{K}
\end{array}\right]} \\
& =\left[\begin{array}{c}
a_{1} \\
a_{2}
\end{array}\right]+\left[\begin{array}{lllll}
b_{1,1} & b_{1,2} & b_{1,3} & b_{1,4} & b_{1,5} \\
b_{2,1} & b_{2,2} & b_{2,3} & b_{2,4} & b_{2,5}
\end{array}\right]\left[\begin{array}{c}
\hat{\delta}_{i} \\
\operatorname{PRVOL}_{i} \\
\operatorname{EXPENS}_{i} \\
\operatorname{TYPE}_{i} \\
\operatorname{HOUSE}_{i}
\end{array}\right]+\left[\begin{array}{c}
\mu_{1, i} \\
\mu_{2, i}
\end{array}\right],
\end{aligned}
$$

for $i=1 \ldots 24$. Because the values for the dependent variables are characterized by differing degrees of estimation accuracy, OLS may yield biased estimates if heteroscedasticity is present. However, based on the White test, no heteroscedasticity was found in any of the individual regressions, and we therefore applied OLS instead of WLS (Verbeek, 2000). Note further that $\hat{\delta}_{i}$ and $H O \hat{U} S E_{i}$ are estimated parameters used as a predictor variable. While OLS then still results in consistent parameter estimates (Greene, 2000), a correction on the standard errors is called for (see Murphy and Topel, 1985 for an in-depth discussion).

Given our interest in the effect of the respective covariates on the durables' cyclical sensitivity (which is reflected in both the cyclical variability ratio and the dynamic comovement elasticity), we focus on the combined significance of the corresponding parameter estimates using Strube's (1985) meta-analytical test on the $p$-values of the parameter estimates obtained in the two correlated equations. The Strube (1985) test extends the method of adding $Z$ 's (Rosenthal, 1991) to correct for the non-independence of the respective hypothesis tests across both equations.

Detailed results on the estimation of equation (8) can be found in Table $3 .{ }^{16}$ The regressions were found to have a reasonable goodness of fit ( $R^{2}$ above $\left.64 \%\right)$, and the Jarque-Bera statistics for the normality of the residuals showed that the null hypothesis for normally distributed errors cannot be rejected (all $p>0.10$ ).

As expected, the estimates of $b_{1,1}$ and $b_{2,1}$ turned out to be negative $\left(b_{1,1}=-2.080\right.$, $\left.p<0.15 ; b_{2,1}=-2.458, p<0.10\right) .{ }^{17}$ Their combined evidence indicates that industries which increase prices more during economic contractions (more negative $\hat{\delta}_{i}$ ), are found to suffer from a higher cyclical volatility in sales, as the (correlation-corrected) method of added $Z$ 's resulted in a $p$-value of 0.075 .

Some (albeit weaker) support is also found for the moderating role of industry price volatitity on the cyclical sensitivity in sales. In both equations, a negative effect was obtained $\left(b_{1,2}=-12.656 ; b_{2,2}=-13.457\right)$, which resulted in a marginally significant combined effect $(p=0.104)$. Thus, price inertia tends to amplify the cyclical sensitivity in sales, a

15 In the derivation of this 'new-housing elasticity', the one-year lagged effect was included to accommodate for the fact that the construction of a privately-owned house may take more than one year.

16 In the interest of space, the results based on the dynamic comovement elasticity, accounting for a one-year lead and lag effect are reported. Yet, all results remained invariable to the number of dynamics included in the comovement elasticity.

$17 p$-values are one-sided for the directional expectations formulated in Section 6. 
Table 3. Parameter estimates for the moderator analysis of equation (8).

\begin{tabular}{lccc}
\hline & Relative volatility & Comovement & Meta-analytic $p$-value \\
\hline Industry price reaction & -2.080 & $-2.458^{\mathrm{c}}$ & 0.075 \\
Industry price stability & -12.656 & -13.457 & 0.104 \\
Expensiveness & 0.443 & -0.480 & 0.508 \\
Type of product: convenience good & $-1.981^{\mathrm{b}}$ & -0.575 & 0.068 \\
Relation with housing starts & $2.574^{\mathrm{b}}$ & $4.641^{\mathrm{a}}$ & 0.000 \\
$\mathrm{R}^{2}$ & 0.641 & 0.663 & \\
\hline
\end{tabular}

${ }^{\mathrm{a}} p<0.01$ (one-sided); ${ }^{\mathrm{b}} p<0.05$ (one-sided); ${ }^{\mathrm{c}} p<0.10$ (one-sided) [all significance levels are computed on the basis of standard errors adjusted for the two-step nature of our parameter estimates; cf. Murphy and Topel, 1985]. Significant effects are indicated in italics.

result consistent with our prior expectation. In sum, both propositions related to industry pricing activities were found to be supported. As such, companies seem to be able to limit the impact of business-cycle fluctuations through an appropriate price strategy.

In contrast, no support was found for the contention that consumers especially refrain from buying more expensive durables during unfavorable economic times. Both parameters, $b_{1,3}$ and $b_{2,3}$, turned out to be insignificant (i.e. $b_{1,3}=0.443, p>0.10 ; b_{2,3}=-0.480, p>$ $0.10)$ and also the meta-analytical $p$-value was nonsignificant $(p=0.508)$.

Convenience goods, however, were found to be less volatile than leisure goods. Both parameter estimates were negative, although only $b_{1,4}$ was significant $\left(b_{1,4}=-1.981, p<\right.$ $\left.0.05 ; b_{2,4}=-0.575, p>0.10\right)$. Most importantly from a hypothesis-testing perspective, Strube's (1985) meta-analytical test showed that their combined effect was significant ( $p=$ 0.068), confirming our prior expectation.

The sales pattern of a number of durables was indeed related to the evolution in newhousing activities. For example, we found a significant cyclical 'new-housing' elasticity of 0.792 for built-in ranges, or 0.630 for trash compactors, while others were not affected at all (e.g. calculators). The mean (median) across all durables was 0.364 (0.349). By including this variable into the regression analyses (equation (8)), it was found that durables that are more closely related to consumer new-housing activities were also affected harder by business-cycle fluctuations. This result holds for both the cyclical volatility $\left(b_{1,5}=\right.$ 2.574, $p<0.05)$ and the comovement elasticity $\left(b_{2,5}=4.641, p<0.01\right)$. Not surprisingly, also the meta-analytic test on both parameter estimates turned out to be highly significant $(p<0.001)$.

To assess the impact of the economic condition during product launch, a 'state of the economy'-dummy variable is added to equation (8). As described in Appendix A, we lose four observations due to missing information on the state of the economy during launch. Immediate inclusion of this variable would have left us with fewer observations to estimate the impact of the aforementioned covariates, and hence reduce the power of their tests. In spite of that, the substantive results with respect to industry price reactions, price volatility, expensiveness, and type of durable remained similar when estimated on the 20 (rather than 24) durables for which the state of the economy-dummy is known. As for the latter, we 
find that the parameter estimates are not significant $(-0.486, p>0.10 ; 0.646, p>0.10$; meta-analytic $p=0.567)$. More research is needed, however, to assess whether this lack of empirical support is due to the absence of the presumed superior quality during product launch, or whether any initial superiority failed to carry over in subsequent contraction periods.

For more mature durables, a larger component of total sales is due to the replacement of existing units (Bayus, 1988; Steffens, 2001). We therefore run our cyclical sensitivity analysis separately on the early vs. later half of the sample period (cf. Clark, Freeman, and Hanssens, 1984). For those durables introduced most recently, however, it could be argued (i) that insufficient data are available to conduct a split-half analysis, and (ii) that they have not yet reached maturity. They could therefore be thought of as being less suited to assess the impact from the importance of replacement purchases, dominant in further stages in the PLC. As such, we exclude the five durables where less than 25 years of sales data are available. ${ }^{18}$ We subsequently regressed all resulting $38(19$ durables $\times 2)$ relative volatility/comovement statistics on a dummy variable $\left(\mathrm{PLC}_{j}\right)$, taking the value of 1 in the later stage of the durables' life cycle and 0 otherwise.

$$
\left[\begin{array}{c}
\sigma\left(c_{j}\right) / \sigma\left(c_{j}^{\mathrm{GNP}}\right) \\
\beta_{j}^{K}
\end{array}\right]=\left[\begin{array}{l}
c_{1} \\
c_{2}
\end{array}\right]+\left[\begin{array}{ll}
d_{1,1} & d_{1,2} \\
d_{2,1} & d_{2,2}
\end{array}\right]\left[\begin{array}{c}
P L C_{j} \\
H O \hat{U} S E_{j}
\end{array}\right]+\left[\begin{array}{c}
v_{1, j} \\
v_{2, j}
\end{array}\right]
$$

for $j=1 \ldots 38$. Again, we add the new-housing elasticity variable $\left(H O \hat{U} S E_{j}\right)$ to control for the complementarities in those durables related to consumer house-building activities. We find that indeed a later stage in the PLC is associated with a lower cyclical volatility $\left(d_{1,1}=-1.518, p<0.01 ; d_{2,1}=-0.111, p>0.10\right)$, although only $d_{1,1}$ was individually significant. ${ }^{19}$ Most importantly, the meta-analysis on both estimates $d_{1,1}$ and $d_{2,1}$ yielded a significant $p$-value of $0.064 .^{20}$ This result is consistent with our argumentation that currently-owned durables may have become indispensable, and, in case of product failure, consumers are more willing to replace them even during an economic contraction. More excessive sensitivity to business-cycle fluctuations in case of trial purchases underscores further the importance of considering such fluctuations in new-product diffusion models, as these models are intended to capture the dynamics in trial purchases.

18 Specifically, calculators, electric knives, hair setters, oral hygiene devices and water pulsators are excluded from the analysis.

19 For the impact of the importance of replacement buying, we did not postulate a directional proposition, so the reported $p$-values for this moderator are two-sided.

20 Ramey and Vine (2003) found an overall decline in the volatility of GNP and durable sales from the mid-1980s onwards. To see whether this general decline in economic volatility drives our results on the replacement hypothesis, we validated this key finding by implementing a split half analysis on a sample restricted to the before-1984 area. In so doing, we lose a number of observations. In line with our earlier approach, we now exclude those durables where the total number of observations prior to 1984 is less than 25 (as a consequence, 8 durables were excluded from our sample). As before, we find that cyclical sensitivity is lower in the later half of the (now pre-1984) sample, as the (meta-analytic) $p$-value is 0.096 . We are thankful to one of the reviewers for pointing out this alternative explanation to us. 


\section{Validation}

We validate our results in several ways. First, we assess the representativeness of our sample, and compare our substantive findings on the extent of cyclical sensitivity to the ones obtained when analyzing total US expenditures on consumer durables. Next, we evaluate whether our asymmetry findings, both in terms of deepness and steepness, can be replicated when adopting a non-parametric testing procedure instead of the parametric skewness approach applied thus far. Finally, we assess to what extent our findings are idiosyncratic to the specific filtering procedure that was adopted to extract the cyclical component from the different sales series. Specifically, the Hodrick-Prescott (HP) filter is introduced as an alternative to the Baxter and King approach adopted in previous sections.

\subsection{Representativeness of the consumer durables in our sample}

The 24 durables included in our analysis involve mainly household appliances. Apart from these appliances, consumers spend a considerable part of their budget on other durables, such as motor vehicles and furniture. To assess whether our empirical generalizations (based on 24 durable series) are representative for the broader set of durable goods typically bought by households, we additionally analyze the cyclical sensitivity in total US expenditures on durables (see Section 6 for a more detailed discussion of this variable).

The results are very comparable. The cyclical volatility statistic for the aggregate durable series is 0.053 . Comparing this value to the volatility in GNP reported in Section 5.1 confirms our earlier observation that business-cycle fluctuations are more strongly pronounced in the context of consumer durables. This finding is in line with the conclusion of Cook (1999) and Hodrick and Prescott (1997), who also study the evolution of aggregate US expenditures on durables. Cook (1999) plotted the cyclical component of US expenditures on both durables and non-durables, and concluded based on a visual inspection of the graph that the former are more vulnerable to business cycles. Hodrick and Prescott (1997), on their part, found that postwar consumer durable expenditures are more than three times as volatile as real GNP. In addition, the mean cyclical comovement derived from the total US expenditures on durables is 2.046, and closely corresponds to the average comovement statistic derived from the 24 durables in our dataset (2.250).

Also the skewness results for total US expenditures on durables confirm our earlier findings. There is again no evidence for deepness asymmetry, as the mean deepness statistic is rather low (mean $D\left(c_{t}\right)=-0.16$ ). The steepness statistic for the aggregate series had an average value of -0.43 , close to the average value across our 24 durables $(-0.40)$.

In sum, these results support the contention that the combined evidence from our 24 consumer durables is indeed generalizable to expenditures on other durable goods in the market.

\subsection{Alternative asymmetry test: non-parametric triples test}

While frequently used and intuitively appealing, the parametric approach proposed by Sichel (1993) to test for cyclical asymmetries has been criticized in that it may lack power to reject 
the null hypothesis of symmetry (Razzak, 2001; Verbrugge, 1997). Low power is certainly a problem for temporally aggregated data, as aggregation may dampen the cyclical properties of the series, and the lack of evidence of asymmetry could therefore be an unfortunate statistical artifact (Mills, 2001). DeLong and Summer (1986a), for instance, tested for asymmetries in US unemployment rates using both quarterly and annual data. Based on the magnitude of the skewness statistic, the annual data suggested as much asymmetry as their quarterly counterparts, but skewness in the annual data turned out to be insignificant.

Even though our meta-analytical procedure already corrects to some extent for the potentially low power of each individual test, we also applied the non-parametric triples test proposed by Verbrugge (1997) and Razzak (2001), which has been argued to be more powerful. We refer to Appendix B for a more detailed exposition on the nature of the triples test.

The asymmetry results based on this non-parametric test are very similar to the results described in Section 5. With respect to deepness asymmetry, five durables had the expected negative sign, close to the seven durables based on the parametric test for deepness. Also the meta-analysis confirmed our conclusions reached before: deepness asymmetry was again strongly rejected, with a (meta) $p$-value of 0.99 . In addition, the steepness results from the triples test support our earlier findings. As before, most durables (17) had a negative skewness statistic. However, we now find that three of these steepness effects are statistically significant (i.e. trash compactors, $p<0.05$; steam irons and electric knives, $p<0.10$ ), which is in line with the presumably higher power of the test. As before, we are able to reject the null hypothesis of symmetry against the asymmetric steepness alternative based on the meta-analysis $(p=0.02)$.

In sum, it is fair to say that the results from the parametric skewness analysis closely coincide with the results based on the non-parametric triples test.

\subsection{Robustness with respect to the filtering technique}

As indicated in Section 3, a crucial issue is how to extract the cyclical component in the time series. The empirical literature on business cycles contains a wide variety of competing filtering methods, which may result in a somewhat different cyclical component (Cogley, 1997), and hence, may also affect the subsequent inferences on the extent and potentially asymmetric nature of the series' cyclicality. We therefore validated our substantive findings through the well-known Hodrick-Prescott filter, which has a long tradition in the economics literature as a method for extracting business cycles (see e.g. Backus and Kehoe, 1992; Cook, 1999; Holly and Stannett, 1995). ${ }^{21,22}$ All our results were found to be very robust; both in

21 In the marketing literature, two well-known and frequently-used detrending procedures are (i) a prior regression on a linear trend (see e.g. Lal and Padmanabhan, 1995), and (ii) the first-difference filter (see e.g. Dekimpe and Hanssens, 1995a). Both filters are less suited to extract the cyclical component from a series. Removing a linear trend is inappropriate when the series contains a unit root (Baxter and King, 1999; Tinsley and Krieger, 1997), a property many marketing time series have (Dekimpe and Hanssens, 1995b). The first-difference filter tends to put a higher weight on the short-term, irregular, component, while down-weighting both the business-cycle component of interest and the long-run component (Baxter, 1994).

22 For technical details, we refer to the studies of Hodrick and Prescott (1980, 1997). 
terms of the cyclical sensitivity, which considerably exceeds the one in GNP, the absence of deepness asymmetry, the combined evidence of steepness asymmetry, and with the exception of one moderator (industry price stability, which was found to be just marginally significant before), the same variables were found to explain the cross-durable variability in cyclical sensitivity. Detailed results on this validation exercise are available from the first author upon request.

\section{Conclusion}

Business cycles can have a profound impact on many companies and industries. Still, not much prior research has systematically considered the extent and nature of cyclical sensitivity in marketing performance. This general neglect of the business-cycle impact in the marketing literature, which was also deplored in a recent call for papers by the Marketing Science Institute (2002), is surprising. Indeed, many managers admit to adjust their marketing practices during contraction/expansion periods (Shama, 1993), while also the consumers' confidence in the state of the economy, as well as their subsequent purchasing patterns, are described as very cyclical in numerous business-press articles (see e.g. Business Week, August 5, 2002; The Economist, March 9, 2002). In addition, this sensitivity can vary widely across both firms and industries.

In this paper, we investigated how business-cycle fluctuations affect sales in various durable industries. First, behavioral theories were discussed that may explain cyclical sensitivity in durable purchases. In addition, we also elaborated on multiple reactions on the part of the companies that might amplify or attenuate the cyclical movements in their sales. To that extent, the key managerial insights from our results relate to (i) the identification of factors that are associated with more/less cyclical sensitivity, which may be useful to managers trying to diversify their activities to reduce the 'cyclical risk' they face, and (ii) our findings on the significant importance of pricing practices in relation to the cyclical sensitivity.

Specifically, we introduced four summary statistics to systematically quantify the extent and nature of business-cycle fluctuations on the sales evolution of 24 consumer durables. We showed that, on average, consumer durables are much more sensitive to business-cycle fluctuations than the general economic activity, as expressed in an average cyclical volatility of more than four times the one in GNP. In addition, durables have a mean cyclical dynamic comovement elasticity in excess of 2 , so that every percentage decrease in the cyclical component of GNP translates in a drop in the cyclical component of durable sales by, on average, more than $2 \%$. These results indicate that when assessing the impact of aggregate economic fluctuations, durable manufacturers should be aware of the fact that consumer durables are far more sensitive than other products, and that relying on aggregate economic indicators can be very misleading. We further analyzed various reasons that may underlie this substantial vulnerability of durables to business-cycle fluctuations. First, we found that consumers tend to postpone their purchases, as evidenced by the presence of asymmetric steepness in durable sales. Second, companies' pricing practices were found to amplify the cyclical sensitivity in durable sales, as companies tend to increase prices during an economic contraction, while decreasing them during an expansion. Indeed, business-cycle 
fluctuations in sales patterns were more pronounced in those industries where such price reactions were larger. In addition, we found evidence for a higher cyclical sensitivity in industries characterized by sticky (inert) pricing practices. Hence, durable industries that are less used to adjust their prices tend to be hit harder by economic downturns. As such, companies have two immediate strategies at hand to reduce their cyclical sensitivity; i.e. to quickly adjust prices in a cyclical (rather than the usual/observed countercyclical) way. Third, the nature of the durable turned out to be important as well. We found leisure goods to be more sensitive to business-cycle fluctuations than convenience goods. Managers should also be aware that intrinsic cyclical fluctuations are likely to become less pronounced in later stages of the product's life, i.e. as replacement purchases become a more substantial fraction of total sales. This observation underscores the importance of having a diversified offering with products in different stages of their life cycle (Harrigan and Porter, 1983).

Limitations and further research. Our analysis is subject to a number of limitations that open immediate avenues for further research. First, we limited the analysis to 24 durable goods, and further research should consider other, durable and non-durable, industries. In particular, it would be interesting to study business-cycle sensitivity in industrial markets, where every change in the demand for consumer goods may cause larger changes in the derived demand for factors of production of those goods (Bishop, Graham, and Jones, 1984). This phenomenon is comparable to the 'bullwhip' effect in the supply-chain literature (see e.g. Hanssens, 1998; Lee, Padmanabhan, and Whang, 1997). Second, our methodological procedure starts by extracting from the sales series those fluctuations that are related to business cycles. Previous research has pointed out that the choice of filtering technique may influence the findings (Cogley, 1997). Although we cannot fully account for this caveat, we did validate our findings using an alternative filter; still, more extensive validation exercises may be feasible along this dimension. Cogley (1997), for instance, proposes to detrend macro-economic series by regressing them on aggregate consumption expenditures for non-durables.

Third, the temporal aggregation level of our data can have some limitations. As different up- and downward phases in the business cycle can also be (partly) present within one year, certain fluctuations in sales may be masked when analyzing yearly data. In addition, as suggested by DeLong and Summer (1986a), temporal aggregation may affect the power of our tests. In the analysis, we tried to accommodate for this in two ways: (i) we performed a meta-analysis that offers a stronger test for the presence (absence) of cyclical asymmetry than the individual impact estimates, and (ii) we validated our asymmetry results using a more powerful non-parametric test. Still, it would be beneficial to reconsider the topic using temporally more disaggregate data. Moreover, when using data at a level of temporal aggregation smaller than one year, the Baxter and King filtering procedure (albeit with somewhat different weights than the ones given in equation (2)) is able to also identify and suppress fluctuations in the series that occur with a periodicity smaller than 2 years (see Baxter and King (1999) and Vilasuso (1997) for more details). This should allow for a better approximation of the range of business-cycle periodicities of 1.5 to 8 years identified by the NBER than when working with annual data.

Fourth, one might also consider a simultaneous estimation of a single full-flexible (potentially nonlinear) model, that might also account for the fact that negative shocks could have a different impact than positive shocks. Alternatively, a full-scale structural model could be 
used to jointly determine price and sales movements over the business cycle. Data availability prevented us from estimating everything into a single comprehensive framework. Yet, our approach is in line with the growing research tradition in marketing of using a two-step procedure to establish Empirical Generalizations (see e.g. Bell, Chiang, and Padmanabhan, 1999; Nijs et al., 2001; Pauwels, Franses, and Srinivasan, 2003; or Steenkamp et al., 2005). In addition, this approach fits the modular decision-making approach advocated by Little (1970). Still, a one-step approach might well result in some efficiency gains (Bolton, 1989).

Fifth, one could argue that our results may be confounded by gradual and/or cyclical quality improvements over time. We believe, however, that the confounding impact from durable quality improvements is rather limited. Long run or gradual quality improvements, as reflected in a durable's changing mean replacement age, may indeed be present (Steffens, 2001). However, our filtering approach removes all long-run developments from the series in a way that they do not intervene with our cyclical findings (see our discussion on the advantages of the Baxter and King filter in Section 3). Alternatively, one might argue that consumers may switch to lower quality (cheaper) products during economic contractions. Yet, we still find empirical evidence that average prices paid increase during contractions, suggesting that our current conclusion may be a conservative one.

Sixth, we only focused on one country, the US, so it is not yet clear whether our results are generalizable to other countries. In addition, we focused on industry-level sales. Shama (1993), however, pointed out that even within one industry, companies may both be affected differently and respond differently to business-cycle fluctuations. More research is needed on the cyclical sensitivity of performance at the company level, where appropriate strategic modification during contraction/expansion periods may give some companies a competitive advantage (see e.g. Srinivasan, Lilien, and Rangaswamy, 2004). More disaggregate, firmspecific information would lead to more detailed managerial recommendations on how firms may reduce the cyclical sensitivity they experience in their own product sales. Finally, we also advocate going into more detail on the potential moderating role of other key marketing variables, such as advertising and promotional activities.

\section{Appendix A: Measurement of moderators}

Industry price reaction. The price reactions assessed in this study relate to price reactions induced by business-cycle fluctuations. As such, we use the same filtering procedure adopted in Section 3 to extract only those price movements that can be related to business cycles. A similar approach to assess the behavior of prices at business-cycle frequencies was adopted by Backus and Kehoe (1992) and Rotemberg and Woodford (1999), among others.

Industry price volatility. Industry price volatility represents the flexibility in durable price adjustments over time. Because price flexibility refers to a company's ability to change prices quickly, we follow Van de Gucht, Dekimpe, and Kwok (1996), and capture short-run price variability by the standard deviation of the first difference in real, over-time prices. To control for the differences in absolute price levels, price volatility is derived on logtransformed data. The mean price volatility among the 24 durables is 0.08 , ranging between 0.04 (dishwashers) and 0.20 (calculators). 
Expensiveness. The expensiveness of a durable is expressed as a percentage of the average annual household income. Following the procedure advocated in Parker (1992), we derive the average annual income of US families by dividing real US GNP by the total number of families in the nation (as published by the US Census Bureau; www.census.gov). Next, deflated durable unit prices were divided by this average annual family income. This yearly value is subsequently averaged over the life cycle of the product. The mean value ranged from $0.05 \%$ (corn popper) to $1.94 \%$ (refrigerators), with an average across all 24 durables of $0.83 \%$.

Type of product. A dummy variable is used to capture the distinction between timesaving convenience goods on the one hand, and 'amusement-enhancing' or leisure goods on the other hand. The dummy variable takes the value of 1 if the durable is classified as a convenience good, and 0 if it is a leisure good. For the 24 durables considered, two of them are classified as leisure goods: black \& white TVs and color TVs (see also Horsky, 1990).

State of the economy during launch. The phase of launch is coded as a dummy variable, taking the value of 1 if the durable's introduction took place during a contraction, and 0 if the introduction took place during an expansion. To determine its value, we compare the durable's launch year, as published in Parker (1992), with the contraction dates proposed by the NBER dating committee (www.nber.org/cycles.html). Some missing launch years are obtained from Agarwal and Bayus (2002) and Golder and Tellis (1997), although for 4 durables (corn poppers, electric knives, hair setters and trash compactors) we could not trace their initial launch year. Any launch year where at least six months are located in a US contraction period (according to the NBER), is considered a contraction launch year, else the introduction year is classified as an expansion launch year. Six durables (blenders, built-in ranges, clothes dryers, electric washers, refrigerators, and vacuum cleaners) were introduced during an economic contraction, while the 14 others were introduced during an expansion. This observation is consistent with Devinney (1990), who showed that the number of new product introductions varies systematically over the business cycle, with relatively fewer introductions during unfavorable economic times.

Importance of replacement buying. During later stages in the product life cycle, replacement purchases make up a larger portion of existing sales (Bayus, 1988; Steffens, 2001). We separate among phases with relatively more first vs. replacement purchases through the durable's phase in the product life cycle, and distinguish between 2 stages, early vs. late (cf. Clark, Freeman, and Hanssens, 1984). Specifically, we create a dummy variable to separate both ( 0 in the early stage, and 1 during the later stage), where the early stage in the durables' life cycle is defined as the first half of the sample period, the later stage is represented by the second half.

\section{Appendix B: Non parametric triples test}

The parametric skewness-based test proposed by Sichel (1993) has been criticized for having only low power to reject the null hypothesis of symmetry, while being sensitive to outliers (Razzak, 2001; Verbrugge, 1997). Therefore, a non-parametric triples test, first developed by Randles et al. (1980), and introduced in the economics literature by Verbrugge (1997), has 
been suggested as an alternative, more powerful test to derive cyclical asymmetry (Razzak, 2001; Verbrugge, 1997).

A triple of observations $\left(X_{i}, X_{j}, X_{k}\right)$ forms a right triple (i.e. is skewed to the right) if the middle observation $\left(X_{j}\right)$ is closer to the smallest observation $\left(X_{i}\right)$ than to the largest observation $\left(X_{k}\right)$. Conversely, a left triple (skewed to the left) is one where the middle observation $\left(X_{j}\right)$ is closer to the larger observation $\left(X_{k}\right)$ than to the smaller observation $\left(X_{i}\right)$. Both triple types are graphically illustrated in the figure below:

Right triple

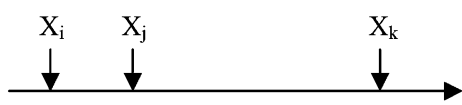

Left triple

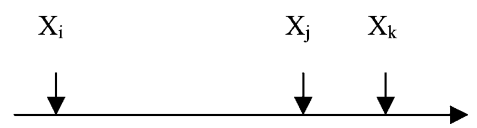

This distinction is formalized through the following function:

$$
\begin{aligned}
& f^{*}\left(X_{i}, X_{j}, X_{k}\right) \\
& \quad=\frac{\left[\operatorname{sign}\left(X_{i}+X_{j}-2 X_{k}\right)+\operatorname{sign}\left(X_{i}+X_{k}-2 X_{j}\right)+\operatorname{sign}\left(X_{j}+X_{k}-2 X_{i}\right)\right]}{3}
\end{aligned}
$$

which can be shown to take on the value of $1 / 3$ in case of a right triple, $-1 / 3$ in case of a left triple, and 0 in case of a symmetric triple.

To formally test for symmetry in business cycles, one should consider all possible triples from the sample (a sample of size $T$ has $\left(\begin{array}{l}T \\ 3\end{array}\right)$ combinations), and determine whether most of the triples are right or left skewed. Applying (B1) to all triples, the following (relative) statistic is obtained:

$$
\hat{\eta}=\left(\begin{array}{l}
T \\
3
\end{array}\right)^{-1} \sum_{i<j<k} f^{*}\left(X_{i}, X_{j}, X_{k}\right)
$$

which can be shown to equal:

$$
\hat{\eta}=\frac{[\text { (number of right triples })-(\text { number of left triples })]}{3\left(\begin{array}{c}
T \\
3
\end{array}\right)}
$$

Obviously, if there are more (less) right triples than left triples, the value for $\eta$ will be positive (negative), while $\eta$ will be zero in case of a perfect symmetric distribution. To test $\eta=0$ against the alternative $\eta<0$, one uses the following test statistic:

$$
\frac{\hat{\eta}}{\sqrt{\hat{\sigma}_{\eta}^{2} / T}}
$$


which can be shown to have a limiting $N(0,1)$ distribution. We refer to the study of Randles et al. (1980) for both a more elaborate discussion/description of the methodology, and for the derivation of $\hat{\sigma}_{\eta}^{2}$.

\section{Acknowledgments}

The authors thank Christophe Croux, Bas Donkers, Inge Geyskens, Dominique Hanssens, Peter Leeflang, Don Lehmann, Koen Pauwels, Jan-Benedict Steenkamp, Piet Vanden Abeele, Christophe Van den Bulte, Frank Verboven, and Dick Wittink for their constructive comments on earlier versions of the paper. This paper also benefited greatly from the constructive comments of the editor, Peter Rossi, and two anonymous reviewers. Finally, the authors gratefully acknowledge financial support from the Marketing Science Institute under grant number no. 4-1200, and from the Flemish Science Foundation under grant number G.0116.04.

\section{References}

Adams, F.G. (1964). "Consumer Attitudes, Buying Plans, and Purchases of Durable Goods: Principal Components, Time Series Approach.” The Review of Economics and Statistics 46(4), 347-355.

Agarwal, R. and B.L. Bayus. (2002). “The Market Evolution and Sales Takeoff of Product Innovations.” Management Science 48(8), 1024-1041.

Allenby, G.M., L. Jen, and R.P. Leone. (1996). "Economic Trends and Being Trendy: The Influence of Consumer Confidence on Retail Fashion Sales.” Journal of Business and Economic Statistics 14(1), 103-111.

Ang, S.H., S.M. Leong, and P. Kotler. (2000). "The Asian Apocalypse: Crisis Marketing for Consumers and Businesses.” Long Range Planning 33, 97-119.

Backus, D.K. and P.J. Kehoe. (1992). "International Evidence on The Historical Properties of Business Cycles." American Economic Review 82(4), 864-888.

Ball, L. and G.N. Mankiw. (1994). "Asymmetric Price Adjustment and Economic Fluctuations.” The Economic Journal 104(423), 247-261.

Barrett, B.W. and M.B. Slovin. (1988). "Economic Volatility and the Demand for Consumer Durables." Applied Economics 20, 731-738.

Baxter, M. (1994). "Real Exchange Rates and Real Interest Differentials. Have We Missed the Business-Cycle Relationship?” Journal of Monetary Economics 33(1), 5-37.

Baxter, M. and R.G. King. (1999). "Measuring Business Cycles: Approximate Band-Pass Filters for Economic Time Series.” The Review of Economics and Statistics 81(4), 575-593.

Bayus, B.L. (1988). "Accelerating the Durable Replacement Cycle with Marketing Mix Variables." Journal of Product Innovation Management 5(September), 216-226.

Bell, D.R., J. Chiang, and V. Padmanabhan. (1999). "The Decomposition of Promotional Response: An Empirical Generalization." Marketing Science 18(4), 504-526.

Berman, J. and J. Pfleeger. (1997). "Which Industries are Sensitive to Business Cycles?” Monthly Labor Review 120(2), 19-25.

Bishop, W.S., J.L. Graham, and M.H. Jones. (1984). "Volatility of Derived Demand in Industrial Markets and Its Management Implications.” Journal of Marketing 48(4), 95-103.

Bolton, R.N. (1989). "The Relationship Between Market Characteristics and Promotional Price Elasticities." Marketing Science 8(2), 153-169.

Bowman, D., D. Minehart, and M. Rabin. (1999). "Loss Aversion in Consumption-Savings Model." Journal of Economic Behavior \& Organization 38(2), 155-178.

Bronnenberg, B.J., C. Mela, and W. Boulding. (2002). “The Periodicity of Competitor Pricing.” Working paper, the Anderson School of Management, UCLA. 
Burns, A.M. and W.C. Mitchell. (1946). Measuring Business Cycles. New York: National Bureau of Economic Research.

Caballero, R.J. (1993). “Durable Goods: An Explanation for their Slow Adjustment.” Journal of Political Economy 101(2), 351-384.

Chevalier, J. and D. Scharfstein. (1996). "Capital-Market Imperfections and Countercyclical Markups: Theory and Evidence.” American Economic Review 86, 703-725.

Chowdhury, A.R. (1994). “Advertising Expenditures and the Macro-Economy: Some New Evidence.” International Journal of Advertising 13, 1-14.

Christiano, L.J. and T.J. Fitzgerald. (1998). “The Business Cycle: It’s Still a Puzzle.” Economic Perspectives 22(4), Federal Reserve Bank of Chicago, 56-83.

Clark, W.A.V., H.E. Freeman, and D.M. Hanssens. (1984). "Opportunities for Revitalizing Stagnant Markets: An Analysis of Household Appliances.” Journal of Product Innovation Management 4(September), 242-254.

Cogley, T. (1997). "Evaluating Non-Structural Measures of the Business Cycle." Economic Review (Federal Reserve Bank of San Francisco) 3, 3-21.

Cook, S. (1999). “Cyclicality and Durability: Evidence from U.S. Consumers’ Expenditure.” Journal of Applied Economics 11(2), 299-310.

Coulson, J. (1979). “Marketing Issues.” Journal of Marketing 43(1), 91.

Cundiff, E.W. (1975). "What is the Role of Marketing in a Recession?” Journal of Marketing 39(2), 1.

Darby, M.R. (1972). "The Allocation of Transitory Income Among Consumers' Assets." American Economic Review 62(5), 928-941.

de Chernatony, L., S. Knox, and M. Chedgey. (1991). "Brand Pricing in a Recession." European Journal of Marketing 26(2), 5-14.

Dekimpe, M.G. and D.M. Hanssens. (1995a). “The Persistence of Marketing Effects on Sales.” Marketing Science 14(1), 1-21.

Dekimpe, M.G. and D.M. Hanssens. (1995b). "Empirical Generalizations About Market Evolution and Stationarity.” Marketing Science 14(3/2), G109-G121.

Dekimpe, M.G., P.M. Parker, and M. Sarvary. (2000). "Global Diffusion of Technological Innovations: A CoupledHazard Approach.” Journal of Marketing Research 37(1), 47-59.

DeLong, B. and L. Summer. (1986a). “Are Business Cycles Asymmetric?” In R. Gordon (ed.), American Business Cycles: Continuity and Change. Chicago: Chicago University Press, pp. 166-179.

DeLong, B. and L. Summer. (1986b). "The Changing Cyclical Variability of Economic Activity in the United States.” In R. Gordon (ed.), American Business Cycles: Continuity and Change. Chicago: Chicago University Press, pp. 679-734.

Devinney, T.M. (1990). "New Products Over the Business Cycle.” Journal of Product Innovation Management 7(December), 261-273.

Dhalla, N.K. (1980). “Advertising as an Antirecession Tool.” Harvard Business Review 58(1), 158-165.

Dobbs, R.F., T. Karakolev, and F. Malige. (2002). "Learning to Love Recessions.” McKinsey Quarterly 2(Special edition), 6-9.

Dutton, J.E. and R.B. Duncan. (1987). "The Creation of Momentum for Change Through the Process of Strategic Issue Diagnosis.” Strategic Management Journal 8(3), 279-295.

Estelami, H., D.R. Lehmann, and A.C. Holden. (2001). "Macro-Economic Determinants of Consumer Price Knowledge: A Meta-Analysis of Four Decades of Research.” International Journal of Research in Marketing 18(4), 341-355.

Franses, P.H. (1994). "Modeling New Product Sales: An Application of Cointegration Analysis.” International Journal of Research in Marketing 11(5), 491-502.

Frantzen, D.J. (1986). "The Cyclical Behavior of Manufacturing Prices in a Small Open Economy.” The Journal of Industrial Economics 34(4), 389-408.

Gale, D. (1996). "Delay and Cycles.” Review of Economic Studies 63(215), 169-198.

Goerne, C. (1991). "Marketers Using More Coupons to Fight Recession.” Marketing News, March 18, 6.

Golder, P.N. and G.J. Tellis. (1997). "Will It Ever Fly? Modeling the Takeoff of Really New Consumer Durables." Marketing Science 16(3), 256-270.

Granger, C.W.J. and M. Hatanaka. (1964). Spectral Analysis of Economic Time Series. Princeton, NJ: Princeton University Press. 
Green, E.J. and R.H. Porter. (1984). “Noncooperative Collusion under Imperfect Price Information.” Econometrica 52(1), 87-100.

Greene, W.H. (2000). Econometric Analysis, 4th edition. Englewood Cliffs, NJ: Prentice Hall.

Hanssens, D.M. (1998). “Order Forecasts, Retail Sales, and the Marketing Mix for Consumer Durables.” Journal of Forecasting 17(3/4), 327-346.

Hanssens, D.M., L.J. Parsons, and R.L. Schultz. (2001). Market Response Models: Econometric and Time Series Analysis, 2nd edition. Boston, MA: Kluwer Academic Publishers.

Hardie, B.G., E.J. Johnson, and P.S. Fader. (1993). "Modeling Loss Aversion and Reference Dependence Effect on Brand Choice." Marketing Science 12(4), 378-394.

Harrigan, K.R. and M.E. Porter. (1983). "End-Game Strategies for Declining Industries.” Harvard Business Review 61(4), 111-121.

Helsen, K., K. Jedidi, and W.S. DeSarbo. (1993). "A New Approach to Country Segmentation Utilizing Multinational Diffusion Patterns.” Journal of Marketing 57(4), 60-71.

Hillier, T. (1999). “Successful Competitive Strategies for Recessions and Recovery: Evidence from PIMS.” In P. Barwise (ed.), Advertising in a Recession. Oxfordshire, United Kingdom: NTC Publications Ltd., pp. 43-51.

Hodrick, R.J. and E.C. Prescott. (1980). "Post-war U.S. Business Cycles: An Empirical Investigation.” Working paper, Carnegie-Mellon University, Pittsburg, PA.

Hodrick, R.J. and E.C. Prescott. (1997). “Postwar U.S. Business Cycles: An Empirical Investigation.” Journal of Money, Credit, and Banking 29(1), 1-16.

Holly, S. and M. Stannett. (1995). "Are There Asymmetries in UK Consumption? A Time Series Analysis." Applied Economics 27(8), 767-772.

Holmes, J.G. and J.K. Rempel. (1989). “Trust in Close Relationships.” In C. Hendrick (ed.), Close Relationships. Review of Personality and Social Psychology 10. Sage Newburry Park, pp. 187-220.

Horsky, D. (1990). “A Diffusion Model Incorporating Product Benefits, Price, Income and Information.” Marketing Science 9(4), 342-365.

Jacobs, J. (1998). Econometric Business Cycle Research. Dordrecht, The Netherlands: Kluwer Academic Publishers.

Kamakura, W.A. and S.K. Balasubramanian. (1987). "Long-Term Forecasting with Innovation Diffusion Models: The Impact of Replacement Purchases.” Journal of Forecasting 6(1), 1-19.

Kamakura, W.A. and G. Gessner. (1986). "Consumer Sentiment and Buying Intentions Revisited: A Comparison of Predictive Usefulness." Journal of Economic Psychology 7, 197-220.

Katona, G. (1975). Psychological Economics. New York: Elsevier Scientific Publishing Co.

Kramer, R.M. (2002). "When Paranoia Makes Sense.” Harvard Business Review 80(7), 62-70.

Krishnamurthi, L., T. Mazumdar, and S.P. Raj. (1992). "Asymmetric Response to Price in Consumer Brand Choice and Purchase Quantity Decisions.” Journal of Consumer Research 19(4), 387-400.

Kumar, V., R.P. Leone, and J.N. Gaskins. (1995). “Aggregate and Disaggregate Sector Forecasting Using Consumer Confidence Measures.” International Journal of Forecasting 11(3), 361-377.

Lal, R. and V. Padmanabhan. (1995). “Competitive Response and Equilibria.” Marketing Science 14(3), G101G108.

Lee, H.L., V. Padmanabhan, and S. Whang. (1997). “The Bullwhip Effect in Supply Chains.” Sloan Management Review 38(3), 93-102.

Leeflang, P.S.H., D.R. Wittink, M. Wedel, and P.A. Naert. (2000). Building Models for Marketing Decisions. Dordrecht, The Netherlands: Kluwer Academic Publishers.

Lemon, K.M., T.B. White, and R.S. Winer. (2002). "Dynamic Customer Relationship Management: Incorporating Future Considerations into the Service Retention Decision.” Journal of Marketing 66(1), 1-14.

Li, V.E. and C.-Y. Chang. (2004). "The Cyclical Behavior of Household and Business Investment in a Cash-inAdvance Economy.” Journal of Economic Dynamics \& Control 28, 691-706.

Little, J.D.C. (1970). "Model and Managers: The Concept of a Decision Calculus.” Management Science 16(8), 467-485.

Macé, S. and S.A. Neslin. (2004). "The Determinants of Pre- and Postpromotion Dips in Sales of Frequently Purchased Goods.” Journal of Marketing Research 41(3), 339-350.

Mahajan, V., E. Muller, and F.M. Bass. (1990). "New Product Diffusion Models in Marketing: A Review and Directions for Research.” Journal of Marketing 54(1), 1-26. 
Mankiw, G.N. (1985). "Consumer Durables and the Real Interest Rate.” The Review of Economics and Statistics 67(3), 353-362.

Marketing Science Institute. (2002). MSI/AAAA Special Request for Proposals: Marketing in Turbulent Times. Cambridge, MA.

Marn, M.V., E.V. Roegner, and C.C. Zawada. (2003). "The Power of Pricing.” McKinsey Quarterly 1, 26-40.

Mascarenhas, B. and D.A. Aaker. (1989). "Strategy Over the Business Cycle." Strategic Management Journal 10(3), 199-210.

Mayhew, G.E. and R.S. Winer. (1992). "An Empirical Analysis of Internal and External Reference Prices Using Scanner Data.” Journal of Consumer Research 19(2), 62-70.

Mehra, Y.P. (2001). “The Wealth Effect in Empirical Life-Cycle Aggregate Consumption Equations.” Federal Reserve Bank of Richmond Economic Quarterly 87(2), 45-68.

Mills, T.C. (2001). "Business Cycle Asymmetry and Duration Dependence: An International Perspective.” Journal of Applied Statistics 28(6), 713-724.

Murphy, K.M. and R.H. Topel. (1985). "Estimation and Inference in Two-Step Econometric Models." Journal of Business and Economic Statistics 3(4), 370-379.

Neftçi, S.N. (1984). "Are Economic Time Series Asymmetric Over the Business Cycle?" Journal of Political Economy 92(2), 307-328.

Newey, W. and K. West. (1987). "A Simple Positive Semi-Definite Heteroscedasticity and Autocorrelation Consistent Covariance Matrix.” Econometrica 55(3), 703-708

Nicosia, F.M. (1974). “The Macro Roles of the Advertising Institution.” In F.M. Nicosia (ed.), Advertising, Management, and Society. New York: McGraw-Hill Book Company, pp. 161-205.

Nijs, V.R., M.G. Dekimpe, J-B.E.M. Steenkamp, and D.M. Hanssens. (2001). "The Category Demand Effects of Price Promotions." Marketing Science 20(1), 1-22.

Nooteboom, B., H. Berger, and N.G. Noorderhaven. (1997). "Effect of Trust and Governance on Relational Risk." Academy of Management Journal 40(2), 308-338.

Parker, P.M. (1992). "Price Elasticity Dynamics Over the Adoption Life Cycle." Journal of Marketing Research 29(3), 358-367.

Parker, P.M. and R. Neelamegham. (1997). "Price Elasticity Dynamics Over the Product Life Cycle: A Study of Consumer Durables.” Marketing Letters 8(2), 205-216.

Parsons, L.J. and W.A. Henry. (1972). "Testing Equivalence of Observed and Generated Time Series Data by Spectral Methods.” Journal of Marketing Research 9(4), 391-395.

Pauwels, K., P.H. Franses, and S. Srinivasan. (2003). "Reference-Based Transitions in Short-Run Price Elasticity." Working paper, Tuck School of Business at Dartmouth.

Petersen, B. and S. Strongin. (1996). "Why are Some Industries More Cyclical than Others?” Journal of Business \& Economic statistics 14(2), 189-198.

Putler, D.S. (1992). “Incorporating Reference Price Effects into a Theory of Consumer Choice.” Marketing Science 11(3), 287-309.

Ramey, V. and D. Vine. (2003). "Tracking the Sources of the Decline in GDP Volatility: An Analysis of the Automobile Industry.” Working Paper, University of California, San Diego.

Randles, R.H., M.A. Fligner, G.E. Policello II, and D.A. Wolfe. (1980). "An Asymptotically DistributionFree Test for Symmetry Versus Asymmetry." Journal of the American Statistical Association 75(369), 168172.

Razzak, W.A. (2001). "Business Cycle Asymmetries: International Evidence.” Review of Economic Dynamics 4(1), 230-243.

Rigby, D. (2001). “Moving Upward in the Downturn.” Harvard Business Review 79(6), 98-106.

Rogers, E.M. (1983). Diffusion of Innovations. New York: The Free Press.

Rosenthal, R. (1991). Meta-Analytic Procedures for Social Research, Newbury Park: Sage.

Rotemberg, J.J. and G. Saloner. (1986). "The Supergame-Theoretic Model of Price Wars During Booms.” The American Economic Review 76(3), 390-407.

Rotemberg, J.J. and M. Woodford. (1999). “The Cyclical Behavior of Prices and Costs.” In J.B. Taylor and M. Woodford (ed.), Handbook of Macroeconomics. Amsterdam: Elsevier Science B.V., pp. 1051-1135.

Ruppert, D. and B. Aldershof. (1989). "Transformations to Symmetry and Homoscedasticity." Journal of the American Statistical Association 84(406), 437-446. 
Rust, R.T., J.J. Inman, J. Jia, and A. Zahorik. (1999). “What You Don’t Know About Customer-Perceived Quality: The Role of Customer Expectation Distributions.” Marketing Science 18(1), 77-92.

Shama, A. (1993). "Marketing Strategies During Recession: A Comparison of Small and Large Firms." Journal of Small Business Management 31(3), 62-72.

Shea, J. (1995). "Union Contracts and the Life-Cycle/Permanent-Income Hypothesis." The American Economic Review 85(1), 186-200.

Sichel, D.E. (1993). “Business Cycle Asymmetry: A Deeper Look.” Economic Inquiry 31(2), 224-236.

Srinivasan, R., G.L. Lilien, and A. Rangaswamy. (2004). "Turning Adversity into Advantage: Does Proactive Marketing During a Recession Pay Off?” International Journal of Research in Marketing, forthcoming.

Steenkamp, J-B.E.M., V.R. Nijs, D.M. Hanssens, and M.G. Dekimpe. (2005). "Competitive Reactions to Advertising and Promotion Attacks." Marketing Science, forthcoming.

Steffens, P.R. (2001). "An Aggregate Sales Model for Consumer Durables Incorporating a Time-Varying Mean Replacement Age.” Journal of Forecasting 20(1), 63-77.

Stock, J.H. and M.W. Watson. (1999). "Business Cycle Fluctuations in US Macroeconomic Time Series.” In J. Taylor and M. Woodford (eds.), Handbook of Macroeconomics. Amsterdam: Elsevier, pp. 3-64.

Strube, M.J. (1985). "Combining and Comparing Significance Levels from Nonindependent Hypothesis Tests." Psychological Bulletin 97(2), 334-341.

Taylor, J.B. (1999). "Staggered Price and Wage Setting in Macroeconomics.” In J. Taylor and M. Woodford (eds.), Handbook of Macroeconomics. Amsterdam: Elsevier, pp. 1009-1050.

Taylor, L.D. and D. Weiserbs. (1972). “Advertising and the Aggregate Consumption Function.” The American Economic Review 62, 642-655.

Tellis, G.J., S. Stremersch, and E. Yin. (2003). “The International Takeoff of New Products: The Role of Economics, Culture and Country Innovativeness." Marketing Science 22(2), 188-208.

Thaler, R. (1985). "Mental Accounting and Consumer Choice.” Marketing Science 4(3), 199-214.

Tinsley, P.A. and R. Krieger. (1997). "Asymmetric Adjustments of Price and Output.” Economic Inquiry 35(3), $632-653$.

Tirole, J. (2001). The Theory of Industrial Organization. Cambridge, MA: MIT Press.

Tversky, A. and D. Kahneman. (1991). "Loss Aversion in Riskless Choice: A Reference-Dependent Model." Quarterly Journal of Economics 106(4), 1039-1061.

Van de Gucht, L.M., M.G. Dekimpe, and C.C.Y. Kwok. (1996). "Persistence in Foreign Exchange Rates.” Journal of International Money and Finance 15(2), 191-220.

Van den Bulte, C. (2000). "New Product Diffusion Acceleration: Measurement and Analysis." Marketing Science 19(4), 366-380.

Van Heerde, H.J. (1999). "Models for Sales Promotion Effects Based on Store-Level Scanner Data." Doctoral Dissertation, University of Groningen, Groningen, The Netherlands.

Verbeek, M. (2000). A Guide to Modern Econometrics. Chichester: John Wiley \& Sons, Ltd.

Verbrugge, R. (1997). "Investigating Cyclical Asymmetries.” Studies in Nonlinear Dynamics and Econometrics 2(1), 15-22.

Vilasuso, J.R. (1997). "The Relationship Between Cash Flow and Investment in the United States at Business Cycle Frequencies.” Applied Economics 29(10), 1283-1293.

Yang, C.Y. (1964). "Variations in the Cyclical Behavior of Advertising.” Journal of Marketing 28(2), 25-30.

Zand, D.E. (1972). “Trust and Managerial Problem Solving.” Administrative Science Quarterly 17(2), $229-239$. 